
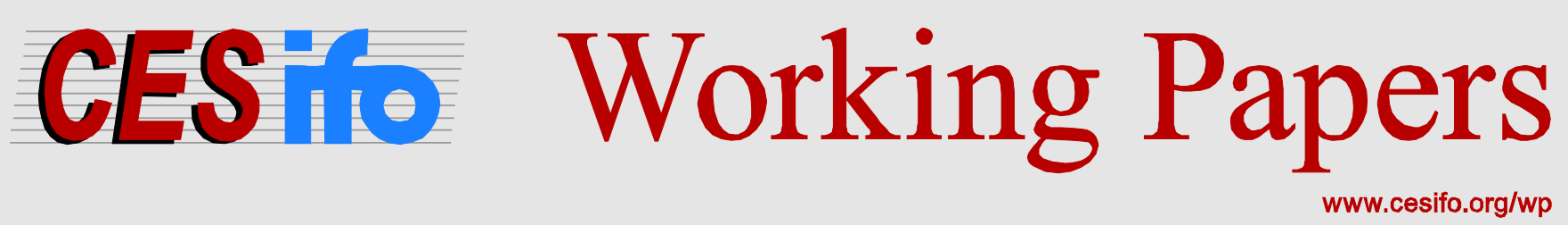

\title{
On the Widely Differing Effects of Free Trade Agreements: Lessons from Twenty Years of Trade Integration
}

\author{
Scott L. Baier \\ Yoto V. Yotov \\ Thomas Zylkin
}

CESIFO WORKING PAPER NO. 6174

CATEgory 8: TRAde Policy

NOVEMBER 2016

An electronic version of the paper may be downloaded

- from the SSRN website:

- from the RePEc website:

WWw.SSRN.com

- from the CESifo website:

www.RePEc.org

www.CESifo-group.org/wp

\section{CESifo}




\title{
On the Widely Differing Effects of Free Trade Agreements: Lessons from Twenty Years of Trade Integration
}

\begin{abstract}
We develop a novel two-stage methodology that allows us to study the empirical determinants of the ex post effects of past free trade agreements (FTAs) as well as obtain ex ante predictions for the effects of future FTAs. We first identify 908 unique estimates of the effects of FTAs on different trading pairs for the years 1986-2006. We then employ these estimates as our dependent variable in a "second stage" characterizing the heterogeneity in these effects. Interestingly, most of this heterogeneity ( 2/3) occurs within FTAs (rather than across different FTAs), with asymmetric effects within pairs (on exports vs. imports) also playing a important role. We offer several intuitive explanations for these variations. Even with the same agreement, FTA effects are weaker for more distant pairs and for pairs with otherwise high levels of ex ante trade frictions. The effects of new FTAs are similarly weaker for pairs with existing agreements already in place. In addition, we are able to relate asymmetries in FTA effects to each country's ability to influence the other's terms of trade. Out-of-sample predictions incorporating these insights enable us to predict direction-specific effects of future FTAs between any pair of countries. A simulation of the general equilibrium effects of TTIP demonstrates the importance of our methods.
\end{abstract}

JEL-Codes: F130, F140, F150.

Keywords: free trade agreements, international trade, gravity.

Scott L. Baier

John E. Walker Department of Economics

Clemson University

USA - Clemson, SC 29634

sbaier@clemson.edu
Yoto V. Yotov

School of Economics

Drexel University

USA - Philadelphia, PA 19104

yotov@drexel.edu

Thomas Zylkin

Department of Economics \& GPN@NUS

National University of Singapore

Singapore 117570

ecsztb@nus.edu.sg

October 28, 2016

Thomas Zylkin is grateful for research support from the NUS Strategic Research Grant (WBS: R-109-000-183-646) awarded to the Global Production Networks Centre (GPN@NUS) for the project titled "Global Production Networks, Global Value Chains, and East Asian Development”. Other acknowledgements will be added later. 


\section{Introduction}

After a quarter century of unprecedented trade integration, primarily in the form of free trade agreements (FTAs), the world may be close to witnessing the culmination of two of the largest trade integration efforts ever. The proposed Trans-Atlantic Trade and Investment Partnership (between the U.S. and E.U.) and Trans-Pacific Partnership (spanning twelve different economies across North America, South America, and the Asia-Pacific region) will, if enacted, collectively make $60 \%$ of the world's production more interdependent by eliminating barriers to trade. Political opposition within many key countries has proven fierce, however. Policymakers and electoral candidates across the political spectrum have expressed doubts that these agreements will bring prosperity to their individual nations, echoing the concerns of workers who feel spurned by past globalization. Excluded non-member countries also have voiced concerns, in their case that these deals will damage their economies via trade diversion. While characterizing the gains from trade has always been a primary concern for economists, the question of how to quantify ex ante the effects of trade liberalization — which increasingly goes beyond the simple elimination of tariffs-remains open and, on the eve of TTIP and TPP, more relevant than ever.

The proliferation of new FTAs in recent years offers a useful historical lens for gaining insights into the potential effects of these future agreements. Since 1986, there have been more than 350 new trade agreements notified to the WTO, which have differed in terms of their aim, breadth, and scope. Broadly speaking, however, a shared objective of many of these agreements has been to achieve "deeper" integration, i.e., economic integration that goes beyond tariff reduction and extends into policies that are more difficult for economists to quantify. Leading econometric studies of the "average partial effect" of FTAs on trade, such as Baier and Bergstrand (2007) and Anderson and Yotov (2016), generally support this view, as the estimates they obtain appear too large to be explained by tariff reductions alone. ${ }^{1}$

\footnotetext{
${ }^{1}$ For example, Baier, Bergstrand and Feng (2014) find that "deeper" agreements have stronger effects and Baier, Bergstrand and Clance (2015) find that ex post FTA effects can depend on ex ante geographic and institutional frictions, such as bilateral distance and the sharing of a common legal system. Incorporating more specific variation in agreement types (e.g., the inclusion of certain provisions) should be regarded as an important direction to pursue, but efforts thus far have only yielded mixed results (see: Kohl, Brakman and Garretsen 2015.)
} 
As a result, those wishing to model the effects of FTAs ex ante face a fundamental problem: how to assess their initial, partial equilibrium impact on bilateral trade. If FTAs affect trade only through tariffs, this partial effect could be computed directly (assuming a constant elasticity). However, in combination, the small current levels of tariffs and the large FTA estimates from the existing literature support the conclusion that the effects of FTAs on bilateral trade go far beyond the simple elimination of tariffs. To allow for such possibilities, a growing number of researchers use econometric estimates of the ex post effects of existing FTAs (often just a single average estimate) as a proxy for the effects of future agreements. ${ }^{2}$ However, aside from variation in tariffs (or, more nebulously, in "non-tariff barriers"), few theoretically-grounded arguments exist for why these partial effects might differ systematically across different agreements.

Accordingly, the main goal of this paper is to develop methods and hypotheses that will identify meaningful, theoretically-motivated sources of variation for predicting the effects of trade deals $e x$ ante. In particular, we pursue a "two-stage" estimation procedure for quantifying and studying heterogeneity in the effects of FTAs. We do so using a data set covering trade and production in manufacturing between 70 countries for the period 1986 to 2006. In a first stage, following Zylkin (2015), we expand on the methods of Baier and Bergstrand (2007) and Bergstrand, Larch and Yotov (2015) to allow for and to obtain agreement-specific effects of each FTA signed during the period, as well as "direction-of-trade"-specific estimates for each member pairing within any given agreement. This stage of the analysis delivers a total of 908 direction-specific, widelyvarying FTA estimates, which we then use as a dependent variable in a second stage which studies the determinants of this variance.

To help explain the heterogeneity in the impact of FTAs, we seek guidance from theory. Specifically, we exploit the basic structure of a standard multi-country trade model to examine two novel and appealing sources of variation in this arena. First, all else equal, pairs of countries with higher levels of trade frictions ex ante should have more potential for larger FTA partial effects ex post.

\footnotetext{
${ }^{2}$ Aichele, Felbermayr and Heiland (2014), Felbermayr et al. (2014), Anderson, Larch and Yotov (2015a), and Carrère, Grujovic and Robert-Nicoud (2015) each use econometric estimates of the average effect of past agreements to model the effects of TTIP (as well as TPP, in the case of Carrère, Grujovic and Robert-Nicoud, 2015).
} 
Second, drawing on the influential "terms of trade" arguments of Bagwell and Staiger $(1999,2004)$, countries with less "market power" over their own terms of trade should receive relatively larger concessions when they sign FTAs, because they are likely already close to their "politically optimal" set of trade policies. To operationalize these insights, we introduce two new, theoretically derived indices: (i) a comprehensive index of "pre-FTA trade barriers", which we obtain naturally from our econometric first stage model, and (ii) a simulated measure of each member of an agreement's "terms of trade sensitivity", which, to emphasize the connection with the theories of Bagwell and Staiger (1999, 2004), we also refer to as an index of "revealed market power". Our second stage analysis finds robust evidence for both of these hypotheses.

We also confirm two other hypotheses we find similarly appealing. First, countries with a prior trade agreement already in place tend to enjoy weaker partial effects from any subsequent agreements. Second, even after controlling for the level of existing trade frictions, FTA partial effects are weaker for countries which are further apart geographically. This may be because more distant countries are more sensitive to changes in trade policies (as emphasized in Baier, Bergstrand and Clance, 2015) or perhaps because they find it more difficult to coordinate on deeper integration because of weaker cultural affinities.

In addition, in light of the apparent trend towards larger multilateral trade blocs, an especially appealing aspect of our two-stage approach is that we can easily narrow our focus to heterogeneous effects that might occur within individual agreements. ${ }^{3}$ Interestingly, we find that variation in FTA effects across different agreements (i.e., the difference between NAFTA and MERCOSUR) explains only about one-third of the variation in our first stage estimates of FTA effects. Of the remaining two-thirds, which are due to "within agreement" heterogeneity, almost half (i.e., almost one-third of the total) are due to asymmetric effects within pairs, or "within pair" heterogeneity. With the exception of prior agreements, our key variables of interest remain relevant when we limit

\footnotetext{
${ }^{3}$ Very few papers in the literature allow for the same agreement to have different effect on different members. Baier, Bergstrand and Clance (2015) allows for this type of heterogeneity by interacting their EIA dummies with $e x$ ante pair-specific relationships, rather than conditioning on agreement-specific variables. Our two-stage approach combines the perspective of Baier, Bergstrand and Clance (2015) with that of Zylkin (2015), who allows for directionof-trade-specific effects within NAFTA.
} 
attention to heterogeneity within agreements. We are also specifically able to relate asymmetries in trade barrier reductions to differences in market power, as would be predicted by "terms of trade" theory.

We also subject these insights to a battery of checks gathered from other possible motivations for trade creation, including "gravity" relationships, factor endowment differences, and institutional frictions to trade. These additional regressions reveal several useful auxiliary findings. For example, we show that FTA effects are larger for countries with larger economic size (GDP), but, conditional on size, asymmetries in FTA effects tend to favor the exports of countries with low GDP per capita. Countries with better institutions as measured by high rule of law, high degree of democracy, and/or high human capital endowments tend to sign stronger agreements. However, we find that these indicators are generally less relevant for explaining heterogeneity "within agreements" and (especially) "within pairs".

One other variable that has been highlighted in the broader literature on FTAs also draws our attention. Following the work of Kehoe and Ruhl (2013) on the "new goods" margin of trade - as well as subsequent work by Kehoe, Rossbach and Ruhl (2015) - we test whether countries who trade a relatively small range of products ex ante have more potential for "explosive" trade creation after the signing of an FTA. Interestingly, we find that the number of products trade ex ante is, if anything, positively related to the amount of trade creation ex post, seemingly contradicting these earlier findings. Two remarks help reconcile this apparent discrepancy. First, to the extent that a low traded goods margin manifests itself in a "gravity" framework as high trade costs, our comprehensive index of "pre-FTA trade barriers" already takes this margin into account. Second, the distinction between "across-" verus "within-" agreement heterogeneity is again important here. In particular, when we restrict our focus to asymmetric FTA effects within the same pair of countries - better approximating the case study design used in Kehoe and Ruhl (2013) and Kehoe, Rossbach and Ruhl (2015) - we do find that a low traded goods margin helps predict asymmetries in trade creation.

By design, our two-stage approach lends itself well to the practical question of how to develop 
and validate a model for making ex ante predictions. Drawing on the machine learning literature, we use an "out-of-sample" prediction analysis to test if one can use an empirical model fitted from the first stage estimates of one set of agreements to reliably predict the partial effects found in the excluded agreements. ${ }^{4}$ As an illustration, we use the predictive model developed from our out-of-sample analysis to generate predicted unique, direction-of-trade-specific partial effects of TTIP on trade between potential TTIP members. Compared with an alternate scenario in which TTIP has only a common average partial effect on all TTIP trade flows, as is typically assumed in other analyses, we find that allowing for heterogeneous partial effects has important consequences for the welfare effects of TTIP, which we are able to relate directly to the sources of variation we identify in our empirical analysis.

Naturally, our approach is complementary to the prevailing, non-econometric methods that have been used to model the effect of trade policies ex ante. Because FTAs have shifted their focus away from tariffs, applied work in the CGE literature increasingly aims to quantify the impact of non-tariff provisions of FTAs on so-called "non-tariff barriers". However, as discussed in Fugazza and Maur (2008), because of the complexity of these issues, even the best-possible estimates of non-tariff barriers must be interpreted with caution and model results based on these estimates may be highly fragile to minor variations in methodology. Our methods admittedly lack the specificity of a fully-specified CGE framework. Nonetheless, we are able to offer the literature several broad sources of variation in FTA effects that have been previously overlooked, have strong theoretical and intuitive appeal, and appear to have robust support in the data.

Lastly, because we allow FTA effects to differ by agreement, we also contribute to a longstanding literature that has examined the effects of individual agreements. This literature begins with the seminal work of Tinbergen (1962), who found only small effects for the Benelux and British Commonwealth preference arrangements, and also includes other influential studies by Frankel and Wei (1997) and Carrère (2006), who allow for differences across several major modern regional trading blocs. Methodologically, the most related work in this area is Kohl (2014), who observes that FTA

\footnotetext{
${ }^{4}$ In practice, we drop one agreement at a time, then try to predict its effects out of sample.
} 
effects may differ based on WTO membership and on the institutional quality of an agreement. By and large, these studies have not found that most FTAs have increased trade. For example, Kohl (2014) finds only $27 \%$ of FTAs have had positive and significant effects on trade. We, however, find positive effects for a majority (57\%) of the agreements in our study. This could be for two main reasons. First, we follow the econometric recommendations of Santos Silva and Tenreyro (2006) in using a Poisson PML estimator, as opposed to OLS, in order to account for heteroskedasticity of trade data and to be able to use the information contained in zero trade flows when estimating the effects of FTAs. Second, we include consistently-measured internal trade flows, which enable us to capture the possibility that the increase in trade between liberalizing countries may actually be at the expense of internal trade..$^{5}$

The following section describes the first stage of our estimation procedure, in which we recover individual-level estimates for every FTA in our sample. Section 3 adds details on how we construct our data and key variables. Section 4 then summarizes our first stage FTA estimates. These estimates are then used as the dependent variables in our second-stage analysis, which is contained in section 5. Section 6 then uses the insights from the second stage to forecast the effects of TTIP. Finally, section 7 adds concluding remarks.

\section{Decomposition of FTA Effects}

This section describes our approach to recover heterogeneous estimates of the effects of FTAs. The "first stage" estimates we obtain here will then serve as our dependent variable in our second-stage analysis in Section 5. As a baseline, we start by specifying an estimating equation for the "average partial effect" of an FTA. We then discuss how to decompose this average effect into successively nested layers of heterogeneity, starting with the level of the individual agreement and then allowing for an increasingly more detailed heterogeneity within agreements as well.

\footnotetext{
${ }^{5}$ This idea has been explored by Dai, Yotov and Zylkin (2014) and by Bergstrand, Larch and Yotov (2015). Our data improve on existing studies by adding more countries and an extended time coverage that will enable us to cover more agreements. The sample covers the years 1986-2006 and includes 455 different newly formed FTA pairs.
} 


\subsection{Structural gravity}

As our starting point, we specify a simple, generalized version of the "structural gravity" equation, as originally popularized by Eaton and Kortum (2002) and Anderson and van Wincoop (2003) and as extended to the panel dimension by Baier and Bergstrand (2007). More recently, Arkolakis, Costinot and Rodríguez-Clare (2012), Costinot and Rodríguez-Clare (2014), and Head and Mayer (2014) have each shown that the basic empirical structure implied by these earlier papers - gravity estimation with exporter and importer fixed effects - is consistent with a very wide range of quantitative trade models, including - but not limited to - the seminal models found in Armington (1969), Krugman (1980), Melitz (2003), and Melitz and Ottaviano (2008).

A suitably generalized way of presenting structural gravity is the following: let $X_{i j}$ denote the value of exports from an origin country $i$ to a destination country $j$. Our gravity equation for these trade flows is

$$
X_{i j}=\frac{A_{i} w_{i}^{-\theta} \tau_{i j}^{-\theta}}{\sum_{i} A_{i} w_{i}^{-\theta} \tau_{i j}^{-\theta}} E_{j}
$$

In (1), $E_{j}$ is the total expenditure by purchasers in $j$ on goods across all different origins (i.e., including goods produced domestically in $j$ ). The share of $j$ 's expenditure, which is allocated to products from any one origin $i$, is directly dependent on the following three factors: $A_{i}$, the overall quality of the production technologies available in $i$; $w_{i}$, the wage paid to factors of production in $i$; and $\tau_{i j}$, the degree of iceberg trade costs required to send goods from $i$ to $j$. Goods from different origins are assumed to be imperfectly substitutable; therefore, the effects of production costs and trade costs on trade are subject to a constant trade elasticity $\theta>1$. Importantly, all cost factors only weigh on trade relative to the overall degree of competition in $j$ 's import market, which is accounted for via the summation term in the denominator of (1). Noting that this summation term is specific to the importing country (because it sums across all origins), a more compact way of 
writing (1) is

$$
X_{i j}=\frac{A_{i} w_{i}^{-\theta} \tau_{i j}^{-\theta}}{P_{j}^{-\theta}} E_{j},
$$

where $P_{j}^{-\theta}=\sum_{i} A_{i} w_{i}^{-\theta} \tau_{i j}^{-\theta}$. Coined by Anderson and van Wincoop (2003) as the "inward multilateral resistance", $P_{j}$ serves as a useful aggregate of all bilateral trade costs faced by consumers in importer $j .{ }^{6}$ Writing the structural gravity equation as in (2) - with distinct $i, j$, and $i$-by- $j$ components - lends itself naturally to deriving a "fixed effects" estimation equation for trade flows, as we demonstrate below.

\subsection{Panel implementation}

For our purposes, the combined trade frictions parameter, $\tau_{i j}^{-\theta}$, is our primary object of interest. We are not, however, interested in the general determinants of trade frictions - e.g., geographical distance, historical affinities, etc. - which have been widely explored in the broader gravity literature. ${ }^{7}$ Rather, we wish to focus on how free trade agreements (FTAs) have shaped changes in $\tau_{i j}^{-\theta}$ over time. More specifically, we aim to shed light on how different agreements have had very different effects on $\tau_{i j}^{-\theta}$ and, furthermore, how changes in $\tau_{i j}^{-\theta}$ may vary widely even within the same agreement. Later, in our second-stage analysis, we will then look at how we can explain and possibly even predict - the variation in these effects based on observable variables.

Our starting point for estimation is to follow Baier and Bergstrand (2007) in deriving a panel implementation of (2) that permits identification of an average FTA effect across all the agreements in our sample. To ease this derivation, we first add a time subscript, $t$, as well as an error term, $\varepsilon_{i j, t}$,

\footnotetext{
${ }^{6}$ As shown in Anderson and van Wincoop (2003), one can also derive a seller-side analogue to $P_{j}$ (the "outward multilateral resistance") that similarly aggregates bilateral trade costs for producers in exporter $i$. By performing this exercise, Anderson and van Wincoop (2003) show how (1) can be re-written in the form of a more traditional gravity equation, in which both countries" "economic mass" (i.e., GDP) enters directly. Anderson and Yotov (2010) and Larch and Yotov (2016) add more detail on the useful properties of the multilateral resistance indices in this context.

${ }^{7}$ For a thorough reference, see Anderson and van Wincoop (2004).
} 
and re-write (2) in exponential form:

$$
X_{i j, t}=\exp \left(\ln A_{i, t} w_{i, t}^{-\theta}+\ln \frac{E_{j, t}}{P_{j, t}^{-\theta}}+\ln \tau_{i j, t}^{-\theta}\right)+\varepsilon_{i j, t}
$$

Next, we introduce a generic functional formulation for the trade costs term $\ln \tau_{i j, t}^{-\theta}$ :

$$
\ln \tau_{i j, t}^{-\theta}=Z_{i j} \delta+\beta F T A_{i j, t}+u_{i j, t}
$$

where $Z_{i j}$ can be thought of a set of time-invariant controls for the the general level of trade costs between $i$ and $j$ with coefficient vector $\delta$. For more traditional gravity applications, the contents of $Z_{i j}$ would normally be specified to include geographical and/or historical ties between countries, as discussed above. For our purposes, however, the sole variable of interest is $F T A_{i j, t}$, a single dummy variable that equals 1 if $i$ and $j$ belong to a common free trade agreement at time $t$ (and zero otherwise). A key insight from Baier and Bergstrand (2007) is that specific knowledge of $\delta$ is neither necessary nor sufficient in order to obtain consistent estimates of $\beta$, the coefficient on $F T A_{i j, t}$. Instead, drawing on standard panel estimation techniques described in Wooldridge (2002), Baier and Bergstrand (2007) recommend using pair-specific fixed effects in place of $Z_{i j} \delta$, such that the time dimension of the panel identifies the causal effect of $F T A_{i j, t}$ on trade.

Implementing the methods of Baier and Bergstrand (2007) in our setting, substituting the definition of the bilateral trade costs, and using fixed effects to control for any country-specific characteristics on the exporter and on the importer side results in the following specification for estimating the average effect of FTAs on trade barriers as

$$
X_{i j, t}=\exp \left(\eta_{i, t}+\psi_{j, t}+\gamma_{i j}+\beta F T A_{i j, t}\right)+\varepsilon_{i j, t}
$$

Here, $\eta_{i, t}$ and $\psi_{j, t}$ are, respectively, time-varying exporter- and importer- fixed effects meant to absorb the $\ln A_{i, t} w_{i, t}^{-\theta}$ and $\ln E_{j, t} / P_{j, t}^{-\theta}$ terms in (3), which are endogenous and cannot be observed directly. In addition (and by extension), $\eta_{i, t}$ and $\psi_{j, t}$ also can be said to control for all country- 
level macroeconomic factors that are not specifically related to bilateral trade frictions between $i$ and $j$ (e.g., productivity shocks, exchange rate fluctuations, terms of trade changes, etc.). $\gamma_{i j}$ is a (symmetric) pair-wise fixed effect that strips out all time-invariant determinants of trade barriers between $i$ and $j .{ }^{8} \quad$ All time-variation in trade costs therefore occurs though the $F T A_{i j, t}$ dummy. Lastly, we treat the additive residual term $\varepsilon_{i j, t}$ as both reflecting measurement error in trade values as well as now also absorbing the error term in $\ln \tau_{i j, t}^{-\theta}$ above. Following the recommendations of Santos Silva and Tenreyro (2006, 2011), we estimate (4) - as well as all subsequent specifications described in this section - using the Poisson Pseudo-maximum Likelihood (or "PPML") estimator.9

We obtain our final baseline specification for estimating the effects of FTAs by incorporating the methods of Bergstrand, Larch and Yotov (2015), who argue that FTA estimates based on specification (4) may be biased upward because they may be capturing the effects of globalization. The simple adjustment proposed by Bergstrand, Larch and Yotov (2015) is to explicitly control for the effects of globalization in the gravity model by introducing a set of globalization dummies. Applied to our setting, this adjustment results in the following econometric model:

$$
X_{i j, t}=\exp \left(\eta_{i, t}+\psi_{j, t}+\gamma_{i j}+\beta F T A_{i j, t}+\sum_{t} b_{t} \cdot \mathbf{I}(i \neq j)\right)+\varepsilon_{i j, t}
$$

where the added term is $\sum_{t} b_{t} \cdot \mathbf{I}(i \neq j)$, a set of dummies that equal 1 for international trade observations (as opposed to internal trade, $X_{i i}$ ) at each time $t$. The coefficients on these time-varying border dummies, the $b_{t}$ 's, capture the process of globalization over time, as all countries trade more with each other and less with their own internal markets.

\footnotetext{
${ }^{8}$ In practice, Baier and Bergstrand (2007) estimate (5) in log-changes, such that the pair fixed effects drop out of the estimation. Because we estimate in levels using symmetric fixed effects, our specific implementation draws more directly on Anderson and Yotov (2016). Later, when we allow for asymmetric FTA effects, it is necessary to also use asymmetric pair effects in order to obtain unbiased estimates. In general, however, imposing symmetry on the pair effects leads to more efficient estimates, because it reduces the number of parameters that need to be estimated. Thus, we stick with symmetric pair effects for our initial specifications.

${ }^{9}$ By using PPML, we implicitly assume that the the variance of $\varepsilon_{i j, t}$ is proportional to the conditional mean of $X_{i j, t}$. Santos Silva and Tenreyro (2006) show that PPML generates relatively robust results even when this assumption is not satisfied and/or the data features many zero trade values. Arvis and Shepherd (2013), Fally (2015), and Anderson, Larch and Yotov (2015b) offer further reasons for PPML's suitability in the gravity context. Egger and Staub (2014) and Head and Mayer (2014) provide a broader comparison between PPML and other, non-GLM estimators not considered in Santos Silva and Tenreyro (2006). Piermartini and Yotov (2016) offer a broader discussion of the econometric challenges associated with gravity estimation as well as recommended best practices.
} 
More importantly for our purposes, the specific interpretation of the FTA coefficient in (5), " $\beta$ ", can be described in one of two ways. From a strictly econometric point of view, $\beta$ is the average partial effect of an FTA on bilateral trade flows, noting that FTAs also influence trade through the country-specific terms $\eta_{i, t}$ and $\psi_{j, t}$. A second, more structural interpretation is that $\beta$ gives the average treatment effect of an FTA specifically on "trade costs" - i.e., its effect on the $\ln \tau_{i j, t}^{-\theta}$ term in (3). For this latter interpretation, it is helpful to note that the combined term $\exp \left(\gamma_{i j}+b_{t}+\beta F T A_{i j, t}\right)$ describes the predicted level of $\tau_{i j, t}^{-\theta}$ in place between countries $i$ and $j$ at time $t$.

To comment more thoroughly on the identification of $\beta$, note that increases in observed trade between $i$ and $j$ do not translate directly to implied reductions in the trade $\operatorname{cost}$ term $\ln \tau_{i j, t}^{-\theta}$. Instead, due to the presence of the time-varying exporter and importer fixed effects, $\beta$ is only identifiable when trade increases between $i$ and $j$ relative to each country's trade with all other partners. Importantly, and consistent with theory, the set of outside partners for each country fundamentally includes the value for $X_{i i}$, the value of sales to one's own market, or "internal trade". We regard accounting for internal trade as a key feature of our empirical approach, since theory dictates that internal trade should be considered an essential component of the overall reference group for a given FTA pairing, especially when one or both partners has an especially large domestic market. Accordingly, as documented empirically in Dai, Yotov and Zylkin (2014), including internal trade in the estimation should lead to larger, more precise estimates of FTA effects. ${ }^{10}$

\subsection{Allowing for FTA heterogeneity}

With the wide adoption of Baier and Bergstrand's methods, most estimates of $\beta$ in the prior literature generally find positive and significant results (We do as well.) ${ }^{11}$ However, for the purposes of policy analysis, an obvious weakness of estimating an "average" FTA effect is that the effects of a

\footnotetext{
${ }^{10}$ Indeed, as we will later show, our accounting for internal trade allows us to obtain substantially more "optimistic" estimates of the effects of individual agreements than the prior literature.

${ }^{11}$ We note some exceptions to this statement: Frankel, Stein and Wei (1997); Ghosh and Yamarik (2004); Head and Mayer (2014). These papers differ methodologically from the approach outlined in Baier and Bergstrand (2007), however.
} 
given agreement may be substantially different from the average; thus, it may not be appropriate to apply estimates of $\beta$ for making ex ante predictions about the effects of specific FTAs. To capture and analyze this potential heterogeneity in FTA effects, we expand on the initial specification shown in (5) in three successive steps:

First, we consider a specification where FTA effects are allowed to vary at the level of the underlying agreement, similar to the approach taken in Kohl (2014): ${ }^{12}$

$$
X_{i j, t}=\exp \left(\eta_{i, t}+\psi_{j, t}+\gamma_{i j}+\sum_{A} \beta_{A} F T A_{i j, t}+\sum_{t} b_{t} \cdot \mathbf{I}(i \neq j)\right)+\varepsilon_{i j, t}
$$

where we allow for a distinct average partial effect - $\beta_{A}$ - for each individual agreement, using superscript $A$ to index by agreement. This initial refinement allows us to make useful statements about which FTAs in our sample have been more successful than others about promoting trade. However, specification (6) is silent about the possibility that the same agreement may not affect all countries involved in exactly the same way.

Second, we allow for further heterogeneity at the level of each trading pair within an agreement. For example, we allow Sweden's accession to the E.U. in 1995 to have different effects on its trade barriers with Germany vs. its trade barriers with the U.K. The resulting specification is

$$
X_{i j, t}=\exp \left(\eta_{i, t}+\psi_{j, t}+\gamma_{i j}+\sum_{A} \sum_{p \in A} \beta_{A: p} F T A_{i j, t}+\sum_{t} b_{t} \cdot \mathbf{I}(i \neq j)\right)+\varepsilon_{i j, t}
$$

where each $p \in A$ is a pair of countries $(i, j)$ belonging to agreement $A$, counting $(i, j)$ and $(j, i)$ as the same pair. $\left\{\beta_{A: p}\right\}$ then is a set of agreement-by-pair-specific FTA estimates.

Third, we consider the possibility that, even within a given pair, an FTA may not affect trade in both directions symmetrically. For this last refinement, let $d \in A$ denote a unique "directional pair" of countries $(\overrightarrow{i, j})$ belonging to agreement $A$, where the notation $(\overrightarrow{i, j})$ refers specifically to the effect on trade flows where $i$ is the exporter and $j$ is the importer. We thus estimate two effects for each agreement-pair, one for each direction of trade. In addition, since FTAs no longer affect each

\footnotetext{
${ }^{12}$ For earlier work, see also: Frankel and Wei (1997), Soloaga and Winters (2001), and Carrère (2006).
} 
partner equally within a given pair, we now also require that the pair-specific parameter used to identify partial effects in (5)-(7), $\gamma_{i j}$, be asymmetric as well. Accordingly, we use " $\gamma_{i j}$ " to denote pair effects that are direction-specific. We then have the following econometric model:

$$
X_{i j, t}=\exp \left(\eta_{i, t}+\psi_{j, t}+\gamma_{\overrightarrow{i j}}+\sum_{A} \sum_{d \in A} \beta_{A: d} F T A_{i j, t}+\sum_{t} b_{t} \cdot \mathbf{I}(i \neq j)\right)+\varepsilon_{i j, t}
$$

It is this final set of FTA estimates - the $\beta_{A: d}$ 's shown in (8) - which we use for our "second stage" analysis of the empirical determinants of trade integration. We discuss the key features of this second stage in a later section, following our discussion of the data, which we turn to now.

\section{Data Construction}

This section describes the sources and the construction of the data with emphasis on several specially constructed indices used as key regressors in our second-stage analysis in Section 5. These indices include our novel measures of "pre-FTA trade barriers" and "revealed market power", as well as the "new goods" margin of Kehoe and Ruhl (2013).

\subsection{Standard Gravity Variables}

Trade. We construct a data set with information on manufacturing production and trade for a sample of 70 countries over the twenty year period $1986-2006 .{ }^{13}$ Table 12 of Appendix A lists out the countries included. Note that, for computation reasons, we combine 17 countries which do not form any FTAs during the period into a single "Rest of the World" aggregate region. In the end, we arrive at a balanced panel of 53 trading regions observed over the 21 year period 19862006. ${ }^{14}$ Our primary source for bilateral trade flows is the UN COMTRADE database. Since

\footnotetext{
${ }^{13}$ Our focus on manufacturing trade admittedly excludes trade in services as well as agricultural products. We use manufacturing data both because of its wide coverage and completeness and also to maintain comparability with similar studies.

${ }^{14}$ All first stage regressions make use of every single year of the data. Cheng and Wall (2005) have argued against using consecutive years in gravity regressions on the basis that wider intervals allow more time for trade to adjust to changes in trade costs. We have found similar results for the case of four year intervals. We favor using every year
} 
partner countries tend to report different values for same trade flow, we generally use the mean of reported values when possible. If either country fails to report a value, we use the non-missing value.

As noted, an important feature of our data is that it includes values for "internal trade" flows (a.k.a. "domestic sales"). To construct internal trade observations, we combine data on industrylevel gross output from two main sources: the CEPII TradeProd database and UNIDO IndStat. We have selected both the sample of countries and the period of study in order to achieve the widest possible use of the available production data from these sources. Since production values in TradeProd are largely taken from earlier versions of UNIDO IndStat - and further augmented using the the World Bank "Trade, Production, and Protection" database by Nicita and Olarreaga (2007) - we generally use TradeProd to provide production data for earlier years and data from UNIDO to fill in later years where needed. ${ }^{15}$ We also cross-check against the World Bank data to fill in some additional missing values from the beginning of the period. We then construct internal trade values as the difference between the value of a country's gross output and the value of its total exports to other markets. In some isolated cases, however, it is not possible to calculate internal trade values because the production data is either missing or implies a negative value for internal trade. We address these issues in a series of steps. First, we apply linear interpolation between nonmissing values whenever possible. Second, if values are negative or missing only for a particular industry, we apply the average share of expenditure spent on domestic output by that country on other (non-missing) industries. Finally, we extrapolate any remaining missing production values at the beginning or end of the sample using the evolution of that country's industry-level exports. ${ }^{16}$

FTAs. Our starting point for FTA data is the set of FTAs used in Baier and Bergstrand (2007).

because it gives us maximal degrees of freedom for identifying direction-specific FTA effects.

${ }^{15}$ Specifically, the TradeProd data is reported in the ISIC Rev. 2 industry classification, covering 1980 to 2006 , and the IndStat data reports values using the ISIC Rev. 3 classification, covering 1995 to 2009. Because ISIC Rev. 2 industry codes do not map one-to-one to the Rev. 3 industry codes, we construct country-specific concordances based on matched years, using the 4 digit level of industry detail whenever possible. For these matched years, the correlation between the original ISIC Rev. 2 production values and the (post-concordance) IndStat values is .990.

${ }^{16}$ We have also experimented with using the U.S. GDP deflator as an alternate basis for extrapolating missing output, following the procedure used in Anderson and Yotov (2016). Using this alternate method makes virtually no difference for our results. 
We update and cross-check this data against information available via the WTO's website as well as via the NSF-Kellogg Database on Economic Integration Agreements. Table 13 of Appendix A provides a complete summary of the agreements included in our study. Overall, our FTA data covers 65 different agreements, including 8 multilateral trading blocs, 32 bilateral FTAs, and 25 agreements between multilateral blocs and outside partners. ${ }^{17}$ Within these 65 agreements, there are 455 different agreement-pairs, counting as separate any instance where two countries that are already joined via a prior agreement become part of a second agreement (e.g., Canada and the U.S. in the case of NAFTA). Since we estimate two effects per agreement-pair, we are able to estimate $2 \cdot 455=910$ distinct FTA effects in total. ${ }^{18}$

\subsection{Construction of Key Covariates}

Pre-FTA trade barriers. As originally observed by Baier and Bergstrand (2007), the main advantage of using a panel specification with pair fixed effects to identify the effects of trade policies is that the pair fixed effects effectively absorb all bilateral trade frictions in the cross-section. Importantly, this includes any "unobservable" component of trade costs, which otherwise would enter the error term and potentially lead to inconsistent estimates. Therefore, the pair fixed effect $\gamma_{i j}$ in (8) contains potentially very useful information about the full level of ex ante trade barriers between any potential FTA pair, including any unobservable trade costs. However, because $\gamma_{\overrightarrow{i j}}$ is direction-specific, and because of collinearity between $\gamma_{i j}$ and the exporter and importer fixed effects $\eta_{i, t}$ and $\psi_{j, t}$, we cannot directly interpret the values for $\gamma_{i j}$ we recover from the estimation as reflecting "trade barriers" (i.e., the $\tau_{i j}^{-\theta}$ 's). In principle, however, we can identify the average trade level of ex ante trade barriers for trade between a given pair $i, j$ by imposing symmetry on

\footnotetext{
${ }^{17}$ We do not estimate a separate effect for EFTA, since it precedes our study.

${ }^{18}$ We note that since Iceland had no positive exports to Romania in the data before the EFTA-Romania agreement, we could not compute an estimate for the effect of EFTA-Romania on Iceland-Romania exports. Therefore, we do not include the EFTA-Romania estimates for the pair Iceland-Romania. We end up with a total of 908 FTA estimates in our second-stage analysis.
} 
the $\gamma_{i j}$ 's. In practice, we can perform the following regression:

$$
X_{i j, t}=\exp \left(\eta_{i, t}+\psi_{j, t}+\gamma_{i j}+\sum_{t} b_{t} \cdot \mathbf{I}(i \neq j)+\sum_{A} \sum_{d \in A} \widetilde{\beta}_{A: d} F T A_{i j, t}\right)+\varepsilon_{i j, t}
$$

where the tilde superscript on the set of partial effects, the $\beta_{A: d}$ 's reflects that fact that we are constraining these to be the same as we estimated previously from (7) using directional fixed effects. The $\gamma_{i j}$ 's are similarly constrained to be symmetric within pairs.

The combined term " $\gamma_{i j}+b_{t-1}$ " then provides a measure of the average level of trade barriers between $i$ and $j$ the year before the signing of an FTA at time $t$. Since $\gamma_{i j}+b_{t-1}$ is an inverse measure of pre-FTA trade frictions between $i$ and $j$, the natural hypothesis is that it should enter with a negative sign in the second stage. Furthermore, since this measure specifically controls for the magnitude of ex ante trade barriers between a given pair of countries, we can continue to include our gravity variables (ln DIST, COLONY, etc.) and these will now in turn give us more specific inferences about the roles these relationships play in explaining the first stage partial effects (rather than also reflecting the role these variables play in determining the magnitude of initial trade barriers). In our empirical analysis, we will simply refer (with some abuse in terminology) to the combined term " $\gamma_{i j}+b_{t-1}$ " as our "first stage pair fixed effect". A natural hypothesis (which we will later confirm) is that pairs with lower first stage pair FE (reflecting higher ex ante trade barriers) should generally enjoy larger FTA effects ex post. Note also that, in the absence of an FTA, we have that $\tau_{i j}^{-\theta}=e^{\gamma_{i j}+b_{t-1}}$.

"Revealed market power". In order to construct our measure of "terms of trade sensitivity" (or "revealed market power"), we proceed as follows. First, we take a given set of FTA-signing countries in the year before they entered the agreement (e.g., the U.S., Canada, and Mexico in 1993). We then introduce a common partial effect for this set of countries and compute the resulting full general equilibrium change in "terms of trade" in for each country:

$$
\widehat{T o T}_{i}=\frac{\widehat{w}_{i}}{\widehat{P}_{i}}
$$


where, following Anderson and Yotov (2016), our notion of "terms of trade" uses the ratio of a country's producer price to its consumer price (which here is the same as its real wage). ${ }^{19} \mathrm{We}$ repeat this process for every FTA in the sample, using the same average partial effect each time (in our case it is the overall average partial effect, $\beta_{A V G}=0.188$ ) and a (typical) trade elasticity of $\theta=4$. This procedure will deliver $\widehat{T o T}_{i}$ 's for each country in our sample, which are directly comparable and should not be systematically related to the partial effects estimated from the first stage, other than for the reasons we are investigating.

Intuitively, countries whose local prices are more responsive to reductions in trade barriers by other countries (i.e., have high $\ln \widehat{T o T}$ ) have less "market power" over world prices. Thus, guided by theory, our expectation is that countries whose terms of trade exhibit more sensitivity should receive relatively larger bilateral concessions as exporters and/or grant relatively small concessions as importers. The basis for this expectation draws on two prominent arguments from the related literature. First, as demonstrated by Bagwell and Staiger (1999), a country with less influence over world prices ("low market power") should already have ex ante trade policies in place that are already close to the "politically optimal" trade polices obtained ex post after trade negotiations. $^{20}$ Second, the "bilateral opportunism" argument of Bagwell and Staiger (2004) suggests that countries who exert more influence over the terms of trade of their trade partners than vice versa must make deeper commitments when they negotiate bilateral trade agreements, in order to credibly convince their partners they will not use their market power to their advantage in setting future trade policies with other countries. These motivations suggest that the FTA partial effects we observe - the the $\beta_{A: d}$ 's from the first stage - should be larger when the exporting country has less market power over world prices and/or when the importing country has more market power. ${ }^{21}$

\footnotetext{
${ }^{19}$ Another approach to computing terms of trade would be to focus on the ratio of export prices to import prices. See Anderson and Yotov (2016) for further discussion. We note, however, this alternative formulation would have a less direct connection to welfare effects, which is what ultimately matters in the theory.

${ }^{20}$ Eicher and Henn (2011) explore a similar idea in the case of WTO partial effects. Bagwell and Staiger (2011) also explore a similar idea in the case of WTO negotiated tariff reductions.

${ }^{21}$ We note that "market power" is not the same thing as "size". In a many-country world with costly trade frictions, a country's influence on the terms of trade of others depends not only on size differences, but also on how the $N \times N$ system of general equilibrium relationships between all pairs of countries responds to a given change in trade policies, which is captured by our theory-consistent ToT index, which "reveals" the relative market power of any set of FTAsigning countries.
} 
"New goods" margin. For some specifications, we also follow Kehoe and Ruhl (2013) in accounting for the possibility that country pairs who trade a smaller range of product varieties ex ante have more potential for "explosive" trade growth ex post. The measure of the number of traded products we use is the Hummels-Klenow decomposition of the "extensive margin" of trade (Hummels and Klenow, 2005), using Kehoe and Ruhl (2013)'s (pair specific) "least traded goods" cutoff to determine whether to count a variety as traded or not. Specifically, the extensive margin of trade from $i$ to $j$ at time $t-1$ (i.e., the year before an agreement) is constructed as

$$
\text { Ext. } \operatorname{Margin}_{i j, t-1}=\frac{\sum_{p \in \Omega_{i j}} X_{W j, t-1}}{\sum_{p \in \Omega_{W j}} X_{W j, t-1}}
$$

$X_{W j, t-1}$ is the volume of trade that each importer $j$ receives from the world at time $t-1$. Each variety $p$ in (11) is an 5 digit SITC product variety, obtained from COMTRADE and assembled using the same procedures described above for aggregate trade. As in Kehoe and Ruhl (2013), $p$ is only assigned to the "traded goods set" $\Omega_{i j}$ if, when varieties are sorted by trade volume, bilateral trade volume in $p$ lies above the 10th percentile. (11) thus gives us a flexible measure of the share of products exported from $i$ to $j$, weighted by each product's contribution to $j$ 's total imports.

\section{Summarizing FTA estimates}

We generate 4 distinct sets of estimates using equations (5)-(8) using aggregate manufacturing trade flows as our dependent variable. Our estimate of $\beta$ in (5) is the easiest to describe: we estimate $\beta=.188$, with a standard error of $0.049(p<.001)$. This estimate yields the interpretation that, on average, FTAs have a partial effect of $e^{0.188}-1=20.7 \%$ on trade flows.

Agreement-specific estimates. As a first pass at examining heterogeneity in FTA effects, we focus strictly on the agreement-specific effects we obtain by estimating (6). The resulting estimates are shown in Table 1, grouped by sign and significance and listed out in descending order. As an alternative means of conveying the heterogeneity in these effects, we also offer a graphical depiction in Panel (a) of Fig. 1, which presents the distribution of our estimates with their associated $95 \%$ 
Table 1: Estimates of Agreement-Specific FTA Effects

\begin{tabular}{|c|c|c|c|c|c|c|c|c|}
\hline Agreement & $\beta_{A}$ & s.e. & Agreement & $\beta_{A}$ & s.e. & Agreement & $\beta_{A}$ & s.e. \\
\hline Positive effects: & & & $($ cont'd $)$ & & & $($ cont'd $)$ & & \\
\hline EU-Romania & 1.307 & 0.072 & Japan-Mexico & 0.425 & 0.064 & EFTA-Turkey & 0.098 & 0.108 \\
\hline Bulgaria-Turkey & 1.287 & 0.187 & Australia-Thailand & 0.367 & 0.070 & Mercosur-Bolivia & 0.069 & 0.153 \\
\hline Andean Community & 1.250 & 0.163 & Mercosur-Andean & 0.366 & 0.094 & $\mathrm{EU}$ & 0.060 & 0.037 \\
\hline Romania-Turkey & 1.160 & 0.054 & NAFTA & 0.361 & 0.090 & EU-Egypt & 0.034 & 0.055 \\
\hline EU-Bulgaria & 1.153 & 0.100 & EFTA-Morocco & 0.315 & 0.154 & Chile-US & 0.025 & 0.035 \\
\hline Israel-Turkey & 1.149 & 0.375 & Canada-Costa Rica & 0.314 & 0.115 & Pan Arab FTA & -0.001 & 0.144 \\
\hline EU-Poland & 1.054 & 0.041 & Chile-China & 0.282 & 0.123 & Australia-Singapore & -0.015 & 0.227 \\
\hline Costa Rica-Mexico & 0.965 & 0.306 & EU-EFTA & 0.253 & 0.120 & Morocco-US & -0.043 & 0.076 \\
\hline Mercosur & 0.940 & 0.161 & AgadirAgreement & 0.235 & 0.116 & EFTA-Mexico & -0.059 & 0.051 \\
\hline Poland-Turkey & 0.804 & 0.084 & EU-Mexico & 0.222 & 0.065 & EU-Chile & -0.061 & 0.097 \\
\hline EU-Hungary & 0.799 & 0.082 & EU-Tunisia & 0.219 & 0.060 & Canada-US & -0.064 & 0.076 \\
\hline EFTA-Poland & 0.731 & 0.084 & Tunisia-Turkey & 0.163 & 0.067 & ASEAN & -0.147 & 0.141 \\
\hline Hungary-Turkey & 0.709 & 0.124 & Chile-South Korea & 0.138 & 0.040 & EFTA-Singapore & -0.195 & 0.145 \\
\hline EFTA-Romania & 0.691 & 0.172 & & & & Singapore-US & -0.391 & 0.252 \\
\hline Canada-Chile & 0.685 & 0.299 & \multicolumn{6}{|c|}{ Insignificant effects $(p>.05)$ : } \\
\hline Israel-Mexico & 0.633 & 0.068 & Jordan-US & 0.829 & 0.603 & & & \\
\hline EFTA-Bulgaria & 0.605 & 0.157 & CEFTA & 0.387 & 0.289 & Negative effects: & & \\
\hline Colombia-Mexico & 0.589 & 0.170 & Egypt-Turkey & 0.246 & 0.144 & EFTA-Israel & -0.157 & 0.067 \\
\hline Bulgaria-Israel & 0.576 & 0.118 & Mexico-Uruguay & 0.244 & 0.297 & EU-Israel & -0.189 & 0.060 \\
\hline Israel-Poland & 0.576 & 0.081 & Mercosur-Chile & 0.241 & 0.153 & EU-Cyprus & -0.209 & 0.092 \\
\hline Hungary-Israel & 0.537 & 0.247 & Chile-Costa Rica & 0.241 & 0.246 & Australia-US & -0.276 & 0.030 \\
\hline EU-Turkey & 0.491 & 0.072 & Chile-Mexico & 0.235 & 0.418 & Chile-Singapore & -0.981 & 0.048 \\
\hline EFTA-Hungary & 0.463 & 0.156 & Israel-Romania & 0.234 & 0.185 & & & \\
\hline Canada-Israel & 0.445 & 0.027 & EU-Morocco & 0.132 & 0.076 & & & \\
\hline \multicolumn{9}{|l|}{ Summary statistics: } \\
\hline Simple & \multicolumn{8}{|c|}{ Weighted Averages } \\
\hline Median $\beta^{A}$ estimate: & & & 0.281 & \multicolumn{3}{|c|}{ by inverse variance: } & \multicolumn{2}{|l|}{0.236} \\
\hline Mean $\beta^{A}$ estimate: & & & 0.362 & \multicolumn{3}{|c|}{ by number of country-pairs } & \multicolumn{2}{|l|}{0.289} \\
\hline Variance of estimates: & & & 0.203 & \multicolumn{3}{|c|}{ by (\#pairs $\times$ inv. var): } & 0.202 & \\
\hline
\end{tabular}

confidence bounds.

Several features of these results stand out. First, not all the agreement-specific effects we estimate are positive and statistically significant. A fair number $(23 / 65$, or $35 \%)$ are measured to be statistically insignificant at the $p=0.05$ significance level. Others $(5 / 65: 8 \%)$ actually exhibit negative and significant effects. Nonetheless, the fact that we find positive, statistically significant partial effects for the majority (57\%) of the agreements in our sample is re-assuring given the more mixed results found in the prior literature. Kohl (2014), for example, is able to obtain positive and significant effects for only $27 \%$ of the agreements in his study. We attribute the more "optimistic" findings from our analysis to our inclusion of internal trade values in our estimation. As shown in 
Dai, Yotov and Zylkin (2014), internal trade is an important component of the overall reference group for estimating theoretically consistent effects of trade policies; thus, estimations that include internal trade generally obtain larger, more precisely estimated FTA effects. ${ }^{22}$

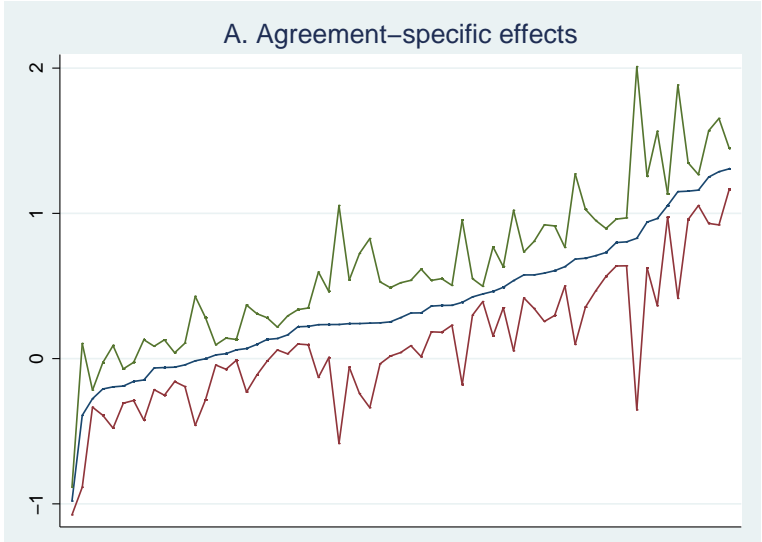

(a)

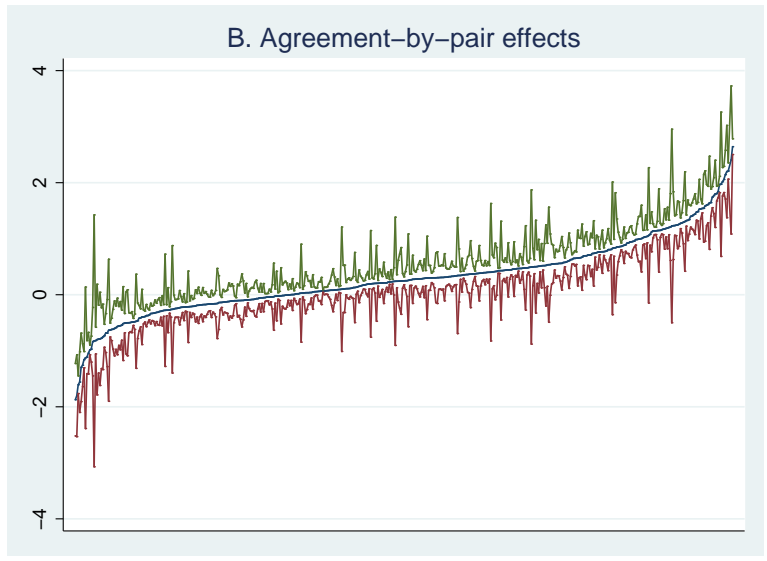

(b)

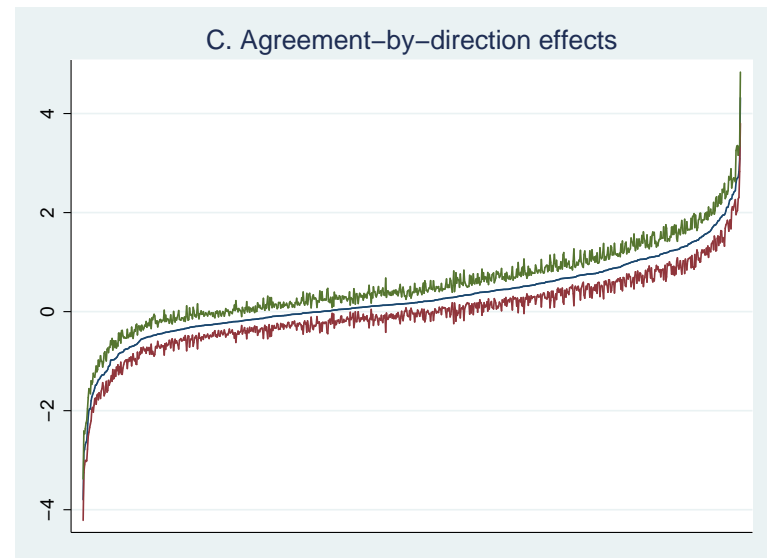

(c)

Figure 1: Distributions of FTA Partial Effects (excluding Romania-Iceland)

Second, we notice that some countries generally seem to have had consistently larger (partial equilibrium) impacts from trade agreements than the other countries in our sample. Central and Eastern European countries in particular (e.g., Bulgaria, Hungary, Romania, Poland) seem to be

\footnotetext{
${ }^{22}$ Indeed, comparing our results with those of Kohl (2014) reveals that our estimates are larger and more significant across the board, while otherwise mostly similar in relative magnitudes. As an experiment, we also estimated agreement-specific effects without including internal trade in the estimation. As expected, the inclusion of internal trade makes a substantial difference: when we drop internal trade observations, only $37 \%$ of FTAs are measured to be positive and significant. The ranking of the different effects from largest to smallest remains similar to the one shown in Table 1. Interestingly, the same is true when we experiment with using OLS (with logged trade flows as the dependent variable) instead of PPML. In this case, the number of agreements with positive and significant estimates drops to 20 , or $31 \%$. Again, the ranking is very similar to Table 1 .
} 
well-represented in the first column of Table 1 . We also note generally strong effects for agreements signed by Israel, Turkey, and Chile. On the other hand, with the exception of Israel and Turkey, other Mediterranean nations - such as Egypt, Tunisia, and Morocco - have generally experienced more modest effects. We will return to this issue of whether some countries consistently experience larger FTA effects than others in our second-stage analysis in Section 5.

Overall, these estimates from Table 1 confirm that the FTAs have had very heterogeneous effects on trade. The degree of heterogeneity we document echoes some earlier findings in the literature, although we generally observe a more optimistic picture of the efficacy of FTAs on an agreement-by-agreement basis. While these factual considerations are useful to note, there remain three important avenues along which we would like to deepen the analysis. First, many agreements involve three or more countries; thus, we wish to examine how the same agreement will affect different pairs of member countries. Second, policymakers generally want to know how trade policies will affect their countries specifically; thus, it is important to allow for direction-specific FTA effects. Third, as noted in Baier, Bergstrand and Clance (2015), even the most finely-tuned appraisals of past FTAs do not by themselves tell us anything about what the effects of future FTAs will look like. We offer some answers and additional insights from our pair- and direction-specific FTA estimates. We will then use these results to build and test an empirical model for making $e x$ ante predictions of FTA effects.

Pair-specific and direction-specific estimates. Given the number of estimates obtained from specifications (7) and (8) - 455 and 910, respectively - it is not practical in this case to present a full listing of the many effects we estimate. Instead, we summarize the heterogeneity we observe in our pair- and direction-specific estimates in two complementary ways. First, in Table 2, we offer a snapshot of the substantial variation in partial effects that can be observed within a single agreement, using the E.U. as our example. Second, in Panels (b) and (c) of Fig. 1, we add graphical depictions of how the distribution of partial effects changes when we allow for more specificity. These graphs can be compared directly with the distribution of agreement-specific effects shown in Panel (a) of Fig. 1. 
We focus on the E.U. because it is by far the largest agreement in our sample. All told, there are 90 distinct pair-specific effects - and 180 direction-specific effects - that can be estimated within the E.U. alone. Rather than show all these estimates, Table 2 presents (roughly) the upper and lower quartiles from the pair-specific effects, as well as some representative examples of pairs.

Table 2: Heterogeneity in EU Accession Effects

\begin{tabular}{|c|c|c|c|c|c|c|c|c|}
\hline Pair & $\beta_{A: p}$ & s.e. & Pair & $\beta_{A: p}$ & s.e. & Pair & $\beta_{A: p}$ & s.e. \\
\hline \multicolumn{9}{|c|}{ Largest EU Accession Effects (by pair): } \\
\hline Hungary-Poland & 2.642 & 0.072 & Poland-Portugal & 0.500 & 0.064 & U.K.-Poland & 0.410 & 0.127 \\
\hline Cyprus-Finland & 1.247 & 0.217 & France-Poland & 0.485 & 0.042 & BLX-Cyprus & 0.408 & 0.154 \\
\hline Hungary-Malta & 1.209 & 0.304 & Cyprus-Netherlands & 0.469 & 0.102 & Austria-BLX & 0.386 & 0.072 \\
\hline Austria-Malta & 0.805 & 0.191 & Spain-Hungary & 0.469 & 0.134 & Spain-Poland & 0.380 & 0.117 \\
\hline Denmark-Hungary & 0.555 & 0.109 & France-Hungary & 0.468 & 0.023 & Germany-Hungary & 0.374 & 0.025 \\
\hline U.K.-Hungary & 0.554 & 0.131 & BLX-Sweden & 0.466 & 0.078 & Hungary-Portugal & 0.366 & 0.172 \\
\hline Finland-Hungary & 0.538 & 0.279 & Hungary-Netherlands & 0.458 & 0.249 & Austria-Spain & 0.335 & 0.081 \\
\hline Cyprus-U.K. & 0.518 & 0.201 & BLX-Finland & 0.434 & 0.075 & Cyprus-Hungary & 0.323 & 0.085 \\
\hline \multicolumn{9}{|c|}{ Small and Negative EU Accession Effects (by pair): } \\
\hline U.K.-Sweden & -0.170 & 0.092 & Spain-Malta & -0.245 & 0.080 & Cyprus-Ireland & -0.466 & 0.162 \\
\hline Ireland-Sweden & -0.175 & 0.118 & Finland-U.K. & -0.263 & 0.071 & Cyprus-Denmark & -0.495 & 0.084 \\
\hline Cyprus-Portugal & -0.188 & 0.165 & Germany-Malta & -0.280 & 0.054 & Finland-Portugal & -0.566 & 0.257 \\
\hline Malta-Netherlands & -0.198 & 0.146 & Finland-Sweden & -0.296 & 0.054 & Italy-Malta & -0.601 & 0.250 \\
\hline Germany-Sweden & -0.207 & 0.063 & Cyprus-Malta & -0.299 & 0.126 & Portugal-Sweden & -0.616 & 0.181 \\
\hline Austria-Sweden & -0.218 & 0.039 & Italy-Sweden & -0.360 & 0.045 & Ireland-Malta & -0.970 & 0.118 \\
\hline Finland-Italy & -0.237 & 0.084 & Denmark-Finland & -0.372 & 0.101 & Cyprus-Poland & -1.159 & 0.074 \\
\hline Finland-Ireland & -0.244 & 0.082 & Denmark-Malta & -0.389 & 0.050 & Greece-Malta & -1.607 & 0.080 \\
\hline Pair & $\beta_{A: d}$ & s.e. & Pair & $\beta_{A: d}$ & s.e. & Pair & $\beta_{A: d}$ & s.e. \\
\hline \multicolumn{9}{|c|}{$\begin{array}{l}\text { Examples of Asymmetric EU Accession Effects } \\
\text { (arrows indicate direction of trade): }\end{array}$} \\
\hline Netherlands $\rightarrow$ Austria & 0.380 & 0.103 & Netherlands $\rightarrow$ Sweden & 0.390 & 0.108 & Spain $\rightarrow$ Sweden & 0.273 & 0.110 \\
\hline Austria $\rightarrow$ Netherlands & -0.393 & 0.112 & Sweden $\rightarrow$ Netherlands & -0.246 & 0.109 & Sweden $\rightarrow$ Spain & -0.138 & 0.098 \\
\hline Poland $\rightarrow$ U.K. & 0.779 & 0.101 & Poland $\rightarrow$ Austria & 0.574 & 0.120 & Poland $\rightarrow$ Netherlands & 0.322 & 0.106 \\
\hline U.K. $\rightarrow$ Poland & 0.053 & 0.099 & Austria $\rightarrow$ Poland & 0.089 & 0.114 & Netherlands $\rightarrow$ Poland & 0.057 & 0.104 \\
\hline Poland $\rightarrow$ Spain & 0.785 & 0.099 & Spain $\rightarrow$ Austria & 0.605 & 0.104 & U.K. $\rightarrow$ Austria & 0.265 & 0.093 \\
\hline Spain $\rightarrow$ Poland & 0.068 & 0.098 & Austria $\rightarrow$ Spain & 0.124 & 0.101 & Austria $\rightarrow$ U.K. & 0.117 & 0.091 \\
\hline Poland $\rightarrow$ Sweden & 0.610 & 0.102 & U.K. $\rightarrow$ Sweden & 0.091 & 0.099 & Sweden $\rightarrow$ Austria & -0.169 & 0.115 \\
\hline Sweden $\rightarrow$ Poland & -0.048 & 0.099 & Sweden $\rightarrow$ U.K. & -0.384 & 0.089 & Austria $\rightarrow$ Sweden & -0.263 & 0.122 \\
\hline
\end{tabular}

From the top panel of Table 2, we can clearly see a very wide variance in the effects of recent E.U. accessions across different E.U. pairs. Interestingly, in this case, the ranking of the various estimates seems somewhat more random than the ordering seen in Table 1. Smaller countries, such as Malta and Cyprus, appear regularly at the extremes of both lists. Other, more economically large countries - such as the U.K., Hungary, and Portugal - also appear multiple times on both lists.

The lower panel of Table 2 shows then some representative examples of E.U. pairs with 
strongly asymmetric E.U. pairs. For brevity, we only show these effects for three acceding countries (Poland, Austria, and Sweden) and three existing E.U. members (Netherlands, Spain, and the U.K.), though these examples are generally representative. Here, we do see strong, countryspecific patterns, confirming again the general pattern suggested by Table 1. Poland's accession has led more so to increases in exports from Poland to existing E.U. members than to increases in trade in the other direction. This dynamic does not appear to be a regular function of E.U. accession, however: asymmetries in the Spain-Austria and Netherlands-Austria pairs both favor trade flows to the acceding country (in these cases, Austria) rather than the other way around. We see also see a similar pattern for Sweden, another acceding country, in its pairings with these countries. Overall, these examples suggest that, even within agreements, there can be large, country-specific patterns of effects that are worth investigating further.

The graphical depictions of the distributions of our various estimates from Fig. 1 echo these same messages and provide a broader overview. ${ }^{23}$ Note first that the relatively wide confidence bands shown in Panel (a) of Fig. 1 suggest substantial variance in within-agreement effects. As these figures collectively show, when we move to increasingly more specific estimates of FTA effects - pair-specific, then direction-specific - the degree of precision in our estimates progressively increases. The reason for this is straightforward. As we have seen with the example of the EU (recalling Table 2), within an agreement, pair-specific and direction-specific FTA effects may vary substantially in magnitudes (and even in signs). As we drill down to the deeper layers of heterogeneity, we remove the possibility that different components of the overall estimate pull in different directions. ${ }^{24}$

Admittedly, as we focus on increasingly specific estimates of changes in trade costs associated with FTAs, we also increase the likelihood that our estimates reflect omitted factors that may enter

\footnotetext{
${ }^{23}$ Baier, Bergstrand and Clance (2015) show similar figures using a random effects model, under the assumption that FTA effects follow a two-tailed normal distribution. We are essentially showing, by estimating explicit dummies for FTA effects, that they do indeed follow a two-tailed distribution. Panels (b) and (c) of Fig. 1 omit one FTA pair - the effects of "EFTA-Romania" on Romania-Iceland trade - since Iceland had not previously exported to Romania before the agreement went into effect.

${ }^{24}$ At the same time, this also means we are identifying these effects based on fewer degrees of freedom. In effect, we are relying more and more on time-variation within individual pairs to identify each individual estimate, as opposed to averaging across different pairs in the same cross-section.
} 
(6) through (8) via the error term. Our identification of these more specific FTA effects depends on the idea that these effects are directly reflected in changes in trade barriers that occurred around the time of the agreement. While this assumption may not strictly hold in all (or even most) cases, presenting these results still allows for a broad description of the vast heterogeneity we observe in the effects of FTAs in our sample, especially within agreements. In addition, while individual FTA effects may be measured with unobservable error, taken collectively, these effects can still be analyzed to determine what factors may be expected to be associated with stronger or weaker effects ex ante. This is the focus of our second-stage analysis, which we develop below.

\section{On the Determinants of the Effects of FTAs}

In this section, we capitalize on the rich database of FTA estimates we have constructed in order to study their determinants. In doing so, we will pursue three objectives. First, we wish to gain a firmer sense of the overall variance in FTA effects and how the successive layers of this variance - across agreements, across pairs within agreements, and within pairs - differ in their relative contributions to this variance. Second, we also wish to explore the feasibility of modeling heterogeneity in FTA effects using observable variables that are potentially related to the effectiveness of an FTA. Importantly, we introduce two new variables that prove to be important determinants of the effects of FTAs: (i) our comprehensive index of "pre-FTA trade barriers", which we hope to use to explain the overall magnitude of FTA partial effects, and (ii) our index of "revealed market power", which we will use to investigate potential asymmetries in FTA effects as well as to test some prominent theoretical predictions drawn from Bagwell and Staiger (1999, 2004). Finally, the empirical insights that we obtain in this section will in turn feed into the out-of-sample and ex ante prediction analysis that will follow in Section 6.

We start the section with a description of our econometric approach and a general characterization of the heterogeneity we observe in our first stage FTA partial effects. We then launch into a "second stage" analysis of how to gauge and decompose the determinants of these effects, incor- 
porating both the two key indices described above as well as other potentially appealing groups of covariates.

\subsection{Econometric Approach}

In general terms, our second-stage analysis takes the direction-agreement-specific partial effects from our estimation of (8) as our dependent variable and regresses them on various covariates of interest in order to understand their determinants. Before turning to the full-blown second-stage analysis, however, we pause first to consider two preliminary matters of interest. First, because our first stage estimates of FTA partial effects have been estimated with error - i.e., the error bands that appear in Fig. 1 - it is important to discuss how this residual enters the second stage and how our analysis may be structured to account for it. An exceptionally useful reference in this regard is Lewis and Linzer (2005), who carefully examine the consequences of various different ways of weighting a "second-stage" regressor to account for residual error variance from a prior stage.

As Lewis and Linzer (2005) demonstrate, so long as a White (1980) correction for heteroscedasticityrobust standard errors is used, simply using (unweighted) OLS to estimate the second stage will enable us to obtain conservative, if inefficient, inferences of our second stage parameters. That is, while other weighting methods might lead to more efficient estimates, the White (1980) correction should still generate reliable consistent estimates of our second-stage standard errors and confidence intervals, such that we should not be worried about "over-confidence" in our inferences. Lewis and Linzer (2005) also demonstrate that other popular weighting methods for dealing with first stage error can actually perform far worse in terms of efficiency and generally conclude that OLS with heteroscedasticity-robust standard errors is "probably the best approach" in most cases.

With these recommendations in mind, we adhere strictly to OLS with robust standard errors for all of our baseline second-stage regressions. We also offer in our Appendix a more detailed treatment of the two other main alternatives considered in Lewis and Linzer (2005), a standard "Weighted Least Squares" (WLS) approach and a special "Feasible Generalized Least Squares" (FGLS) estimator proposed by Hanushek (1974). Auxiliary results show our findings to be similar 
under either of these alternatives, especially FGLS, which Lewis and Linzer (2005) generally find to be the most efficient weighting method.

Second, as more of a direct lead-in for the second stage, we also add more details on how we may decompose the different sources of variance in our first stage FTA estimates and provide a simple and informative initial decomposition. Specifically, we perform a standard "analysis of variance" exercise, sequentially adding agreement-specific followed by (symmetric) pairagreement-specific dummy variables as regressors in order to absorb all variance that is associated with heterogeneity "across agreements" and (respectively) "across pairs within agreements". The remaining variance, that is not specific to either an agreement or a pair within agreement, then strictly reflects asymmetries in FTA effects within pairs of countries.

Table 3: Decomposition of Variance in FTA Effects

\begin{tabular}{llll}
\hline & Source of variance: & & \\
Estimation: & Across agreements & Pairs within agreements & Within pairs \\
\hline OLS & 0.355 & 0.362 & 0.283 \\
WLS & 0.339 & 0.363 & 0.298 \\
FGLS & 0.353 & 0.362 & 0.285 \\
\hline
\end{tabular}

Table 3 documents the results from this decomposition exercise. The results from OLS, our baseline, show that focusing on differences across agreements (which are absorbed using agreementlevel dummies) only explains about $35 \%$ of the overall variation in FTA effects. Looking at the remaining heterogeneity within agreements (which we parse further using pair-agreement-level dummies), a relatively larger share can be explained by variation across pairs. The remaining variance we observe within pairs is still of a comparable order of magnitude to that of the other two components, however. For completeness, we also include variance decomposition results obtained using FGLS and WLS (described further in the Appendix). These are also very similar.

Usefully, this exercise also serves to preview some of the techniques we will use in the analysis that follows to isolate how different variables may explain different aspects of the overall heterogeneity in our estimates. For example, regressing our FTA estimates on a set of observables in the presence of agreement-level fixed effects will allow us to narrowly focus on potential sources of 
"within agreement" heterogeneity. Similarly, the introduction of agreement-by-pair fixed effects will, much as in our initial decomposition exercise, allow us to narrow the focus further to sources of "asymmetries within pairs". Generally speaking, heterogeneity in FTA partial effects within agreements is a topic which has not received much attention in the literature, despite its intuitive appeal. The opportunity to selectively vary our focus in this way will thus be a key aspect of our overall methodology and contribution.

\subsection{Decomposing the Sources of FTA Heterogeneity}

The preceding discussion has highlighted broad patterns of heterogeneity in our first stage FTA estimates. In earlier sections, we have also described at length some attractive, theoretically-guided indices for potentially explaining some of this variance. The stage has now been set for a more detailed investigation: What can we say about the empirical determinants of FTA effects?

In short order, we will introduce a wide variety of covariates that may hold sway in this context, including "economic geography" variables, institutional factors, as well as neoclassical determinants of trade. For now, however, we start with only a basic specification, drawing solely on a few key hypotheses of interest:

$$
\beta_{A: d}=\alpha_{0}+\alpha_{1} \ln \text { First stage pair } \mathrm{FE}_{i j}+\alpha_{2} \ln \widehat{T o T}_{i}+\alpha_{3} \ln \widehat{T o T}_{j}+v_{i j}
$$

As we have established in Section 3.2, each of the key variables in (12) has an intuitive expected sign. The first stage pair fixed effect term, for example, provides a novel and comprehensive (inverse) measure of the level of trade frictions between $i$ and $j$ just before the signing of their agreement. Intuitively, country-pairs with a lower first stage pair fixed effect suffer from higher ex ante bilateral trade frictions and, therefore, have more potential for larger trade creation effects from FTAs ex post. ${ }^{25}$ We would therefore expect the sign of $\alpha_{1}$ to be negative.

\footnotetext{
${ }^{25}$ As discussed in the Data Section, the pair fixed effect term used in our second stage also incorporates our control for the cumulative amount of non-FTA-related "globalization" that has taken place in the years leading up to the signing of each agreement.
} 
$\ln \widehat{T o T}_{i}$ and $\ln \widehat{T o T}_{j}$, meanwhile, are our measures of the sensitivity of each country's terms of trade, which we use to operationalize the influential "terms of trade" arguments of Bagwell and Staiger $(1999,2004)$. The $\ln \widehat{T o T}_{j}$ term, for example, measures the simulated response of the importing country's terms of trade to a generic reduction in trade barriers, e.g., the formation of a trade agreement. If this response is large, it indicates this country has low "market power" over international prices and is therefore likely to already be close to its "politically optimal" set of trade policies, following the parlance of Bagwell and Staiger (1999). Likewise (especially within agreements), we might expect that exporters with less market power (high $\ln \widehat{T o T}_{i}$ in this case) are more likely to receive larger concessions from their larger import partners. In sum, we we would expect to observe $\alpha_{2}>0$ and/or $\alpha_{3}<0$ when we go to estimate (12). Or, at a minimum, we expect $\alpha_{2}-\alpha_{3}>0$, indicating that countries with more market power generally make larger import concessions when they sign trade agreements (and receive smaller concessions in return).

Column 1 of Table 4 shows the basic results from this simple specification testing each of the above hypotheses. While we do not find $\ln \widehat{T o T}_{i}$ to be significant, the other two proposed covariates enter with the expected sign and are highly statistically significant (with $p$-values less than 0.01). As columns 2 to 3 go to show, we generally find the importer's "market power" (embedded in $\ln \widehat{T O T}_{j}$ ) to be more important than the exporters in explaining broad heterogeneity in FTA effects. The difference between these two variables, $\ln \widehat{T o T}_{i}-\ln \widehat{T o T}_{j}$ (shown in the last row of Table 4) is positive and significant, as expected.

Columns 4 through 6 then add several other, more standard variables that specifically draw on the "gravity" literature for inspiration. These include not only bilateral relationships - such as log distance, contiguity, the sharing of a common language, or the presence of a prior free trade agreement - but also the GDPs and GDP per capitas of each partner. For the most part, we do not impose strong priors on these added variables. We do, however, generally expect log distance (or "ln DIST") to be negative, either because more distant countries are more sensitive to changes in trade policies (as emphasized in Baier, Bergstrand and Clance, 2015) or perhaps because they simply sign weaker agreements due to weaker cultural affinities. Likewise, countries 
which already have a prior trade agreement ("Prior Agreement") should experience weaker trade creation than countries without an existing agreement, because the earlier agreements have likely already addressed much of the "low hanging fruit" in terms of easily addressed barriers to trade.

The inclusion of these gravity variables yields several additional results worth noting. The signs on ln DIST and Prior Agreement (in columns 4 and 6) are indeed negative as expected. Of the other bilateral gravity variables we add, only contiguity ("CONTIG”) appears to have any salience for explaining the magnitude of FTA effects. Specifically, we find that contiguous countries experience larger FTA effects. This result may well be due to the same reasons we have already cited for the negative sign we observe on log distance.

Three of the added country-level gravity variables - the log GDPs of both countries and the log per capita GDP of the exporter-also enter the analysis significantly. Interestingly, we find that FTA effects are generally stronger for larger countries (measured in real GDP), both on the exportside as well as on the import-side, with the exporter's GDP having more overall influence. The negative sign on the exporter's development level (i.e., its per capita GDP) could reflect, among other things, the utility of FTAs as a way of circumventing institutional and other developmentrelated barriers to exporting in poorer countries, a hypothesis we will query in more detail below.

What is interesting about including a direct measure of country "size" this way is that, all else equal, we would expect size/GDP to be a reasonable proxy for a country's market power over world prices. Indeed, when GDPs are included, we find that the significance of our $\ln \widehat{T o T}_{j}$ "market power" measure for the importing country weakens to the $p<0.10$ level. Nonetheless, our measure for bilateral differences in market power, $\ln \widehat{T o T}_{i}-\ln \widehat{T o T}_{j}$, remains relatively unchanged versus before.

Lastly, in columns 7 and 8, we also include the Extensive margin (or "New Goods Margin") emphasized in Kehoe and Ruhl (2013). Interestingly, it is significant and positive: conditional on our other covariates, countries which trade a wider range of products with one another ex ante experience stronger trade creation effects from FTAs ex post, contrary to the earlier findings by Kehoe and Ruhl (2013) (as well as subsequent work by Kehoe, Rossbach and Ruhl, 2015). We 
Table 4: Second-stage Estimates: Baseline

\begin{tabular}{|c|c|c|c|c|c|c|c|c|}
\hline & \multicolumn{8}{|c|}{ Dependent variable: First stage directional FTA estimates } \\
\hline & (1) & (2) & (3) & (4) & (5) & $(6)$ & (7) & (8) \\
\hline \multirow[t]{2}{*}{ First stage pair $\mathrm{FE} \dagger$} & $-0.080 * * *$ & $-0.081 * * *$ & $-0.086 * * *$ & $-0.144 * * *$ & $-0.155 * * *$ & $-0.305 * * *$ & $-0.179 * * *$ & $-0.338 * * *$ \\
\hline & $(0.025)$ & $(0.025)$ & $(0.025)$ & $(0.027)$ & $(0.027)$ & $(0.033)$ & $(0.031)$ & $(0.037)$ \\
\hline \multirow[t]{2}{*}{$\ln \widehat{T o T}_{i}$} & -2.189 & & -3.561 & -5.285 & 6.127 & 4.958 & 2.299 & 2.902 \\
\hline & $(4.908)$ & & $(4.811)$ & $(5.087)$ & $(4.665)$ & $(4.561)$ & $(4.659)$ & $(4.677)$ \\
\hline \multirow[t]{2}{*}{$\ln \widehat{T o T}_{j}$} & $-15.966 * * *$ & $-16.154 * * *$ & & $-19.063 * * *$ & -6.417 & $-7.668^{*}$ & $-25.566 * * *$ & $-9.787 * *$ \\
\hline & $(4.259)$ & $(4.353)$ & & $(4.373)$ & $(4.240)$ & $(4.147)$ & $(4.135)$ & $(4.152)$ \\
\hline \multirow[t]{2}{*}{$\ln$ DIST } & & & & $-0.298 * * *$ & & $-0.419 * * *$ & & $-0.392 * * *$ \\
\hline & & & & $(0.035)$ & & $(0.036)$ & & $(0.037)$ \\
\hline \multirow[t]{2}{*}{ CONTIG } & & & & $0.233 * *$ & & $0.209 * *$ & & $0.165 * *$ \\
\hline & & & & $(0.091)$ & & $(0.086)$ & & $(0.083)$ \\
\hline \multirow[t]{2}{*}{ COLONY } & & & & 0.072 & & -0.013 & & -0.016 \\
\hline & & & & $(0.079)$ & & $(0.085)$ & & $(0.085)$ \\
\hline \multirow[t]{2}{*}{ LANG } & & & & -0.123 & & 0.095 & & 0.085 \\
\hline & & & & $(0.075)$ & & $(0.075)$ & & $(0.074)$ \\
\hline \multirow[t]{2}{*}{ LEGAL } & & & & 0.047 & & 0.040 & & 0.044 \\
\hline & & & & $(0.062)$ & & $(0.063)$ & & $(0.062)$ \\
\hline \multirow[t]{2}{*}{ Prior Agreement } & & & & $-0.159 * * *$ & & $-0.200 * * *$ & & $-0.235^{* * *}$ \\
\hline & & & & $(0.053)$ & & $(0.049)$ & & $(0.051)$ \\
\hline \multirow[t]{2}{*}{ Exporter (log) Real GDP } & & & & & $0.146 * * *$ & $0.209 * * *$ & & $0.159 * * *$ \\
\hline & & & & & $(0.022)$ & $(0.023)$ & & $(0.032)$ \\
\hline \multirow[t]{2}{*}{ Importer (log) Real GDP } & & & & & $0.090 * * *$ & $0.152 * * *$ & & $0.152 * * *$ \\
\hline & & & & & $(0.021)$ & $(0.022)$ & & $(0.022)$ \\
\hline \multirow[t]{2}{*}{ Exporter (log) GDP per capita } & & & & & $-0.221 * * *$ & $-0.126 * * *$ & & $-0.184 * * *$ \\
\hline & & & & & $(0.041)$ & $(0.047)$ & & $(0.050)$ \\
\hline \multirow[t]{2}{*}{ Importer (log) GDP per capita } & & & & & -0.040 & 0.054 & & $0.069 *$ \\
\hline & & & & & $(0.038)$ & $(0.038)$ & & $(0.038)$ \\
\hline \multirow[t]{2}{*}{ Extensive margin of trade } & & & & & & & $0.983 * * *$ & $0.644 * * *$ \\
\hline & & & & & & & $(0.146)$ & $(0.222)$ \\
\hline \multirow[t]{2}{*}{ Constant } & $0.269 * * *$ & $0.269 * * *$ & $0.269 * * *$ & $0.271 * * *$ & $0.287 * * *$ & $0.292 * * *$ & $0.272 * * *$ & $0.292 * * *$ \\
\hline & $(0.027)$ & $(0.027)$ & $(0.027)$ & $(0.025)$ & $(0.025)$ & $(0.023)$ & $(0.026)$ & $(0.022)$ \\
\hline Observations & 908 & 908 & 908 & 908 & 898 & 898 & 908 & 898 \\
\hline$R^{2}$ & 0.034 & 0.034 & 0.024 & 0.130 & 0.133 & 0.282 & 0.075 & 0.290 \\
\hline $\ln \widehat{T o T}_{i}-\ln \widehat{T o T}_{j}$ & $13.777 * *$ & & & $13.778 * *$ & $12.544 * *$ & $12.626^{* *}$ & $27.865^{* * *}$ & $12.689^{* *}$ \\
\hline
\end{tabular}

Second-stage estimates are obtained using OLS with robust standard errors (reported in parentheses).

$* p<0.10, * * p<.05, * * * p<.01$

$\dagger$ Also accounts for "globalization" effects.

offer an explanation for this finding below, where we more specifically study the heterogeneity in our FTA estimates that is due to asymmetries within pairs. In addition, we observe a large increase in the magnitude of $\ln \widehat{T o T}_{j}$, especially when GDPs and per capita GDPs are not included (as in column 7). This appears to be because these variables are all at least somewhat correlated: that is, large, rich countries tend to trade a wider variety of products and also tend to have more market power over world prices. 
Within-agreement heterogeneity. As noted earlier, a unique aspect of our two-stage design is that we can easily switch our focus from analyzing broad patterns of heterogeneity (as in Table 4) to the heterogeneity that occurs more narrowly within individual agreements and (later) within individual trading pairs. In addition, this approach will enable us to isolate and test the robustness of our results in the presence of a rich set of fixed effects. In Table 5, we repeat the same specifications used in Table 4, only now with added agreement-level fixed effects. As in our variance decomposition exercise, these agreement-specific dummies soak up all variation in FTA effects at the agreement level, such that our estimates now reflect only the residual variation that takes place within agreements.

Comparing our "within-agreement" results from Table 5 with our earlier results from Table 4 then directly reveals which variables are important for explaining variation within agreements versus across agreements. Broadly speaking, most of our results carry over from before, with a few notable exceptions. For example, when we now focus on within-agreement heterogeneity, it is no longer the importer's "market power" - i.e., its $\ln \widehat{T O T}_{j}$ index - that matters for explaining variation in FTA effects. Instead, it is now the exporter's market power term $-\ln \widehat{T o T}_{i}-$ that becomes relatively more salient. It is positive across all specifications shown in Table 5, still in line with expectations, albeit at a weaker level of significance $(p<0.10)$ in 4 of the 7 columns which include it. The difference in bilateral market power $-\ln \widehat{T o T}_{i}-\ln \widehat{T o T}_{j}-$ remains positive, significant, and, furthermore, remarkably consistent with earlier results from columns 1 to 6 of Table 4. Because the result for the difference in $\ln \widehat{T o T}$ 's appears to be more robust than those for either country-specific term individually, we are inclined to conclude that our constructed measure of market power does probably continue to matter for explaining within-agreement heterogeneity, but may weigh more specifically on asymmetries within pairs, a notion we will return to very shortly.

Other key results from earlier similarly prove to be somewhat fragile when the focus is narrowed to within-agreements. For Prior Agreement, we actually observe a (partial) reversal: it is positive and significant in column 4 of Table 5, seemingly confounding expectations. As columns 
Table 5: Second-stage Estimates: Within-Agreement Heterogeneity

\begin{tabular}{|c|c|c|c|c|c|c|c|c|}
\hline & \multicolumn{8}{|c|}{ Dependent variable: First stage directional FTA estimates } \\
\hline & $(1)$ & $(2)$ & (3) & $(4)$ & $(5)$ & $(6)$ & (7) & $(8)$ \\
\hline \multirow[t]{2}{*}{ First stage pair $\mathrm{FE} \dagger$} & -0.041 & -0.039 & -0.050 & $-0.072 *$ & $-0.155^{* * *}$ & $-0.259 * * *$ & $-0.104 * * *$ & $-0.266 * * *$ \\
\hline & $(0.033)$ & $(0.031)$ & $(0.031)$ & $(0.041)$ & $(0.034)$ & $(0.046)$ & $(0.037)$ & $(0.048)$ \\
\hline \multirow[t]{2}{*}{$\ln \widehat{T o T}_{i}$} & $11.872 *$ & $12.388 * *$ & & $10.182 *$ & $14.291 * *$ & $10.159 *$ & $16.122 * * *$ & $9.739 *$ \\
\hline & $(6.357)$ & $(5.709)$ & & $(5.995)$ & $(5.631)$ & $(5.233)$ & $(6.126)$ & $(5.325)$ \\
\hline \multirow[t]{2}{*}{$\ln \widehat{T o T}_{j}$} & -1.905 & & -5.122 & -3.595 & 1.746 & -2.381 & -7.227 & -2.820 \\
\hline & $(5.525)$ & & $(4.953)$ & $(5.241)$ & $(5.419)$ & $(4.967)$ & $(5.270)$ & $(5.021)$ \\
\hline \multirow[t]{2}{*}{ ln DIST } & & & & -0.106 & & $-0.252 * * *$ & & $-0.237 * * *$ \\
\hline & & & & $(0.077)$ & & $(0.067)$ & & $(0.069)$ \\
\hline \multirow[t]{2}{*}{ CONTIG } & & & & -0.035 & & -0.042 & & -0.051 \\
\hline & & & & $(0.100)$ & & $(0.092)$ & & $(0.090)$ \\
\hline \multirow[t]{2}{*}{ COLONY } & & & & 0.072 & & 0.071 & & 0.062 \\
\hline & & & & $(0.096)$ & & $(0.093)$ & & $(0.092)$ \\
\hline \multirow[t]{2}{*}{ LANG } & & & & -0.043 & & 0.107 & & 0.106 \\
\hline & & & & $(0.087)$ & & $(0.076)$ & & $(0.075)$ \\
\hline \multirow[t]{2}{*}{ LEGAL } & & & & $0.157 * *$ & & $0.204 * * *$ & & $0.202 * * *$ \\
\hline & & & & $(0.071)$ & & $(0.069)$ & & $(0.069)$ \\
\hline \multirow[t]{2}{*}{ Prior Agreement } & & & & $0.205^{* * *} *$ & & 0.009 & & -0.000 \\
\hline & & & & $(0.076)$ & & $(0.074)$ & & $(0.076)$ \\
\hline \multirow[t]{2}{*}{ Exporter (log) Real GDP } & & & & & $0.158 * * *$ & $0.186^{* * *}$ & & $0.169 * * *$ \\
\hline & & & & & $(0.024)$ & $(0.026)$ & & $(0.034)$ \\
\hline \multirow[t]{2}{*}{ Importer (log) Real GDP } & & & & & $0.102 * * *$ & $0.129 * * *$ & & $0.128 * * *$ \\
\hline & & & & & $(0.023)$ & $(0.025)$ & & $(0.025)$ \\
\hline \multirow[t]{2}{*}{ Exporter (log) GDP per capita } & & & & & $-0.131 *$ & -0.072 & & -0.090 \\
\hline & & & & & $(0.079)$ & $(0.079)$ & & $(0.080)$ \\
\hline \multirow[t]{2}{*}{ Importer (log) GDP per capita } & & & & & 0.051 & 0.109 & & $0.114 *$ \\
\hline & & & & & $(0.067)$ & $(0.068)$ & & $(0.068)$ \\
\hline \multirow[t]{2}{*}{ Extensive margin of trade } & & & & & & & $0.668 * * *$ & 0.201 \\
\hline & & & & & & & $(0.144)$ & $(0.216)$ \\
\hline Agreement FEs & $\mathrm{x}$ & $\mathrm{x}$ & $\mathrm{x}$ & $\mathrm{x}$ & $\mathrm{x}$ & $\mathrm{x}$ & $\mathrm{x}$ & $\mathrm{x}$ \\
\hline Observations & 908 & 908 & 908 & 908 & 898 & 898 & 908 & 898 \\
\hline$R^{2}$ & 0.364 & 0.363 & 0.360 & 0.375 & 0.437 & 0.458 & 0.380 & 0.459 \\
\hline Within $R^{2}$ & 0.014 & 0.014 & 0.008 & 0.032 & 0.116 & 0.150 & 0.039 & 0.151 \\
\hline $\ln \widehat{T o T}_{i}-\ln \widehat{T o T}_{j}$ & $13.777 * *$ & & & $13.777 * *$ & $12.544 * *$ & $12.541 * *$ & $23.349 * * *$ & $12.560 * *$ \\
\hline
\end{tabular}

Robust standard errors are reported in parentheses.

$* p<0.10, * * p<.05, * * * p<.01$

6 and 8 show, this may simply be due to the omission of other key covariates such the log real GDPs of each partner and the number of product varieties traded pre-FTA (i.e., the "extensive margin"). Prior Agreement becomes statistically insignificant when these variables are included. This is still contrary to our expectations, but is nonetheless informative regarding how prior agreements places limits the potential for future trade integration. Apparently, these limits are only relevant for determining the overall impact of an agreement on all partners; conditional on a multilateral agree- 
ment being signed (where at least two countries already have an agreement), we cannot identify an effect.

A similar progression also holds for $\ln$ DIST, which becomes negative and strongly significant (as expected) in the presence of log GDPs. As for log GDPs themselves, they both remain positive and statistically significant as before, with exporter real GDP again being having slightly more influence than that of the importer. Development levels (i.e., per capita GDPs), however, exhibit no significant effect here. Rounding out the results from Table 5, the extensive margin is again positive and significant in column 7 (when GDPs are not included), but falls away in column 8 (when they are then added). We also observe that sharing a common legal system also promotes stronger FTA effects within agreements, an effect that was not present earlier when we examined heterogeneity in FTA effects more generally.

Within-pair heterogeneity. To narrow the analysis even further, Table 6 moves from including agreement-level fixed effects (as in Table 6) to now including (symmetric) agreement-by-pair fixed effects. Because these fixed effects by construction absorb all symmetric bilateral variables (e.g., In DIST, etc.), there are only a few key variables that can be identified. In addition, these estimates need to be interpreted very carefully as strictly reflecting determinants of asymmetric FTA effects within pairs. For example, in column 1, we find (as expected) a positive and highly significant sign for $\ln \widehat{T O T}_{i}$. What does this result indicate? Because we cannot here identify both $\ln \widehat{T o T}_{i}$ and $\ln \widehat{T o T}_{j}$ in the same regression, this is simply saying that asymmetries in trade barrier reductions strongly favor the exports of the country with relatively less market power. This to us is the most literal test of the "terms of trade" argument of Bagwell and Staiger (1999). We find it notable that this exercise yields a strong result in favor of the theory.

Turning to other notable frameworks in this arena, column 2 of Table 6 exclusively considers the role of the "extensive margin", which has been emphasized as a predictor of "explosive" trade growth by Kehoe and Ruhl (2013) and Kehoe, Rossbach and Ruhl (2015). ${ }^{26}$ Earlier, in Tables 4

\footnotetext{
${ }^{26}$ Note that our measure for "extensive margin", while bilateral in nature, would typically not be symmetric between pairs.
} 
Table 6: Second-stage Estimates: Heterogeneity within Pairs (Asymmetries)

\begin{tabular}{lllll}
\hline \multicolumn{2}{l}{ Dependent variable: First stage directional FTA estimates } \\
& $(1)$ & $(2)$ & $(3)$ & $(4)$ \\
\hline $\ln \widehat{T o T}_{i}$ & $13.777^{* * *}$ & & $11.595^{* *}$ & $12.511^{* *}$ \\
& $(4.549)$ & & $(5.102)$ & $(4.955)$ \\
Extensive margin of trade & & $-0.268^{* *}$ & -0.152 & $-0.448^{*}$ \\
& & $(0.117)$ & $(0.132)$ & $(0.254)$ \\
Exporter $(\log )$ Real GDP & & & & $0.091^{* * *}$ \\
& & & & $(0.035)$ \\
Exporter $(\log )$ GDP per capita & & & & $-0.130^{* *}$ \\
& & & & $(0.060)$ \\
\hline Agr. $\times$ pair FEs & $\mathrm{x}$ & $\mathrm{x}$ & $\mathrm{x}$ & $\mathrm{x}$ \\
\hline Observations & 908 & 908 & 908 & 898 \\
$R^{2}$ & 0.721 & 0.719 & 0.721 & 0.745 \\
Within $R^{2}$ & 0.013 & 0.007 & 0.014 & 0.073 \\
\hline \hline
\end{tabular}

Second-stage estimates are obtained using OLS with robust standard errors reported in parentheses.

$* p<0.10, * * p<.05, * * * p<.01$

and 5, we found that the number of already-traded product varieties was (if anything) positively associated with the trade creation effect of an FTA. Here, however, when we focus on the extensive margin as a driver of asymmetries, we now find the opposite. This finding helps clarify why our earlier results differ starkly from Kehoe and Ruhl (2013) and Kehoe, Rossbach and Ruhl (2015), since they each examine changes in trade within individual FTA pairings on a case by case basis, which is most similar to our focus on within-pair heterogeneity in Table 6.

The last column of Table 6, column 4, once again confirms that the exporter's economic size (i.e., its $\log$ real GDP) is relatively more important than that of the importer. We also again observe that (conditional on economic size at least), asymmetries in FTA effects seem to favor the exports of the less developed country (in per capita GDP terms).

Institutions and Factor Endowment Differences. To check for additional robustness (and also to satisfy our own curiosity), we go on to consider two further sets of variables that may plausibly be linked to larger FTA effects: (i) "institutional" factors (such as each country's rule of law, the degree of democracy, etc.) and (ii) the role of factor endowment differences and other "Neoclassically" motivated drivers of trade creation. Table 7 investigates the role played by institutions. 
The institutional indicators we consider are: each country's rule of law and bureaucracy quality

Table 7: Second-stage Estimates: The Role of Institutions

\begin{tabular}{|c|c|c|c|c|c|c|}
\hline & \multicolumn{6}{|c|}{ Dependent variable: First stage directional FTA estimates } \\
\hline & $(1)$ & (2) & (3) & (4) & $(5)$ & $(6)$ \\
\hline \multirow[t]{2}{*}{ First stage pair $\mathrm{FE} \dagger$} & $-0.149 * * *$ & $-0.192 * * *$ & $-0.193 * * *$ & $-0.276^{* * *}$ & $-0.242 * * *$ & \\
\hline & $(0.033)$ & $(0.037)$ & $(0.034)$ & $(0.038)$ & $(0.053)$ & \\
\hline \multirow[t]{2}{*}{$\ln \widehat{T o T}_{i}$} & $15.443 * * *$ & $19.471 * * *$ & $12.831 * *$ & $14.747 * *$ & $23.593 * * *$ & $15.157 * * *$ \\
\hline & $(5.763)$ & $(6.056)$ & $(5.879)$ & $(5.857)$ & $(7.814)$ & $(5.426)$ \\
\hline \multirow[t]{2}{*}{$\ln \widehat{T o T}_{j}$} & $-15.799 * * *$ & $-11.605^{*}$ & -5.522 & -2.472 & 7.619 & \\
\hline & $(5.775)$ & $(5.990)$ & $(5.597)$ & $(5.689)$ & $(8.263)$ & \\
\hline \multirow[t]{2}{*}{ Extensive margin of trade } & $1.106^{* * *}$ & $1.091 * * *$ & $1.072 * * *$ & $0.646^{* * *}$ & 0.124 & -0.206 \\
\hline & $(0.164)$ & $(0.165)$ & $(0.214)$ & $(0.234)$ & $(0.233)$ & $(0.285)$ \\
\hline \multirow[t]{2}{*}{ Exporter Democracy } & $0.043 * * *$ & $0.045 * * *$ & $0.046^{* * *}$ & $0.049 * * *$ & -0.014 & 0.008 \\
\hline & $(0.012)$ & $(0.013)$ & $(0.013)$ & $(0.013)$ & $(0.027)$ & $(0.015)$ \\
\hline \multirow[t]{2}{*}{ Importer Democracy } & $0.043 * * *$ & $0.047 * * *$ & $0.042 * * *$ & $0.045 * * *$ & -0.021 & \\
\hline & $(0.011)$ & $(0.011)$ & $(0.010)$ & $(0.011)$ & $(0.027)$ & \\
\hline \multirow[t]{2}{*}{ Exporter Bureaucracy Quality } & $-0.420 * * *$ & $-0.340 * * *$ & $-0.338 * * *$ & $-0.217 * * *$ & -0.042 & -0.086 \\
\hline & $(0.040)$ & $(0.043)$ & $(0.054)$ & $(0.051)$ & $(0.060)$ & $(0.058)$ \\
\hline \multirow[t]{2}{*}{ Importer Bureaucracy Quality } & $-0.242 * * *$ & $-0.167 * * *$ & $-0.229 * * *$ & $-0.119 * * *$ & 0.050 & \\
\hline & $(0.039)$ & $(0.041)$ & $(0.047)$ & $(0.044)$ & $(0.058)$ & \\
\hline \multirow[t]{2}{*}{ Exporter Checks and Balances } & $0.044 * * *$ & $0.044 * * *$ & $0.042 * * *$ & $0.035 * *$ & 0.004 & -0.004 \\
\hline & $(0.016)$ & $(0.016)$ & $(0.015)$ & $(0.015)$ & $(0.015)$ & $(0.017)$ \\
\hline \multirow[t]{2}{*}{ Importer Checks and Balances } & $0.052 * * *$ & $0.046 * * *$ & $0.039 * *$ & $0.028 *$ & 0.005 & \\
\hline & $(0.017)$ & $(0.017)$ & $(0.017)$ & $(0.016)$ & $(0.017)$ & \\
\hline \multirow[t]{2}{*}{ Exporter Rule of Law } & $0.081 * * *$ & $0.064 * *$ & $0.100 * * *$ & $0.063 * *$ & 0.061 & -0.040 \\
\hline & $(0.025)$ & $(0.027)$ & $(0.026)$ & $(0.026)$ & $(0.039)$ & $(0.037)$ \\
\hline \multirow[t]{2}{*}{ Importer Rule of Law } & $0.146 * * *$ & $0.130 * * *$ & $0.154 * * *$ & $0.115^{* * *}$ & $0.105^{* *}$ & \\
\hline & $(0.027)$ & $(0.029)$ & $(0.025)$ & $(0.026)$ & $(0.041)$ & \\
\hline \multirow[t]{2}{*}{ Exporter (log) Real GDP } & & & $0.053^{*}$ & $0.137 * * *$ & $0.187 * * *$ & 0.053 \\
\hline & & & $(0.029)$ & $(0.034)$ & $(0.038)$ & $(0.042)$ \\
\hline \multirow[t]{2}{*}{ Importer (log) Real GDP } & & & $0.113 * * *$ & $0.161 * * *$ & $0.164 * * *$ & \\
\hline & & & $(0.021)$ & $(0.022)$ & $(0.026)$ & \\
\hline \multirow[t]{2}{*}{ Exporter (log) GDP per capita } & & & $-0.222 * *$ & $-0.182 * *$ & -0.122 & -0.064 \\
\hline & & & $(0.086)$ & $(0.082)$ & $(0.104)$ & $(0.098)$ \\
\hline \multirow[t]{2}{*}{ Importer (log) GDP per capita } & & & -0.062 & -0.053 & -0.034 & \\
\hline & & & $(0.059)$ & $(0.055)$ & $(0.076)$ & \\
\hline \multirow[t]{2}{*}{ Constant } & $0.285 * * *$ & $0.299 * * *$ & $0.279 * * *$ & $0.279 * * *$ & & \\
\hline & $(0.026)$ & $(0.026)$ & $(0.025)$ & $(0.025)$ & & \\
\hline Gravity variables & $\mathrm{x}$ & $\mathrm{x}$ & $\mathrm{x}$ & $\mathrm{x}$ & $\mathrm{x}$ & \\
\hline Agreement FEs & & & & & $\mathrm{x}$ & \\
\hline Agr. $\times$ pair FEs & & & & & & $\mathrm{x}$ \\
\hline Observations & 826 & 826 & 816 & 816 & 816 & 816 \\
\hline$R^{2}$ & 0.265 & 0.298 & 0.317 & 0.377 & 0.508 & 0.753 \\
\hline Within $R^{2}$ & & & & & 0.181 & 0.089 \\
\hline $\ln \widehat{T o T}_{i}-\ln \widehat{T o T}_{j}$ & $31.243 * * *$ & $31.077 * * *$ & $18.353 * * *$ & $17.219 * * *$ & $15.974 * * *$ & \\
\hline
\end{tabular}

(each from the Institutional Country Risk Guide), their degree of democracy (from Polity IV), and the degree of "checks and balances" in their respective political systems (from the World Bank's Database of Political Institutions). We note two key elements to keep an eye on. First, we have already observed (especially in Tables 4 and 6) that asymmetries in FTA effects tend to favor the 
exports of countries with low development levels (i.e., low per capita GDP). This plausibly may reflect constraints on developing countries' exports imposed by their weak institutional environment (which FTAs might help circumvent). ${ }^{27}$ Second, the political science literature (see, e.g., Mansfield, Milner and Pevehouse, 2007) has argued that stronger checks and balances and/or a stronger degree of democracy should constrain the ability of an executive to enact more sweeping trade policy changes. Given our access to these variables, we found this hypothesis worth investigating as well.

The results for our institutional development indicators - rule of law and bureaucracy qualityoffer mixed support for the notion that FTAs specifically promote the exports of countries with weak institutions. In columns 1 to 4 of Table 7, which vary the various other regressors included, we generally find that rule of law enters positively and significantly for both countries and that both bureaucracy quality variables enter negatively and significantly. That is, FTAs have stronger effects for countries with strong legal institutions and/or weak bureaucratic institutions. There is indeed an implied asymmetry within both pairs of variables potentially favoring exporters with weaker institutions. Column 8 tests whether these variables are specifically explaining asymmetries in FTA effects within pairs. Neither per capita GDP nor either of these institutional indicators shows up as statistically significant, unfortunately preventing us from drawing firm conclusions on this point. For democracy and checks and balances, we overwhelmingly find that these variables are positively associated with signing stronger agreements. They seemingly play no role, however, in explaining heterogeneity within agreements. Other key results remain virtually unchanged from before.

Table 8 concludes our second-stage analysis by introducing factor endowment differences across countries (e.g., physical and human capital-to-labor ratios, skill-to-labor ratios) as would be prominent drivers of increased trade in Neoclassical "Heckscher-Ohlin"-type frameworks. We also include the absolute difference in these relative endowments, as well as the absolute difference

\footnotetext{
${ }^{27}$ Anderson and Marcouiller (2002) and Manova (2013) both provide evidence that weak institutions are an important barrier to trade for developing countries. Waugh (2010) finds that developing countries generally face higher barriers to exporting than other countries.
} 
Table 8: Second-stage Estimates: Factor Endowment Differences

\begin{tabular}{|c|c|c|c|c|c|c|c|}
\hline & \multicolumn{7}{|c|}{ Dependent variable: First stage directional FTA estimates } \\
\hline & (1) & (2) & (3) & (4) & (5) & (6) & (7) \\
\hline \multirow[t]{2}{*}{ First stage pair FE $\dagger$} & $-0.269 * * *$ & $-0.258 * * *$ & $-0.255^{* * *}$ & $-0.256 * * *$ & $-0.259 * * *$ & $-0.259 * * *$ & \\
\hline & $(0.049)$ & $(0.050)$ & $(0.050)$ & $(0.060)$ & $(0.059)$ & $(0.060)$ & \\
\hline \multirow[t]{2}{*}{$\ln \widehat{T o T}_{i}$} & 0.300 & 0.598 & 0.311 & 9.074 & $13.110 * *$ & 10.248 & $14.362 * * *$ \\
\hline & $(5.041)$ & $(5.144)$ & $(4.989)$ & $(6.119)$ & $(6.578)$ & $(6.709)$ & $(4.854)$ \\
\hline \multirow[t]{2}{*}{$\ln \widehat{T o T}_{j}$} & $-13.595^{* * *}$ & $-13.409 * * *$ & $-13.471 * * *$ & -4.780 & -0.995 & -3.608 & \\
\hline & $(4.439)$ & $(4.366)$ & $(4.371)$ & $(5.855)$ & $(6.233)$ & $(6.556)$ & \\
\hline \multirow[t]{2}{*}{ Exporter (log) Real GDP } & $0.169 * * *$ & $0.144 * * *$ & $0.141 * * *$ & $0.154 * * *$ & $0.152 * * *$ & $0.150 * * *$ & $0.117 * * *$ \\
\hline & $(0.037)$ & $(0.038)$ & $(0.038)$ & $(0.041)$ & $(0.040)$ & $(0.041)$ & $(0.042)$ \\
\hline \multirow[t]{2}{*}{ Importer (log) Real GDP } & $0.106^{* * *}$ & $0.088 * * *$ & $0.087 * * *$ & $0.087 * * *$ & $0.084 * * *$ & $0.083 * * *$ & \\
\hline & $(0.024)$ & $(0.024)$ & $(0.024)$ & $(0.026)$ & $(0.026)$ & $(0.028)$ & \\
\hline \multirow[t]{2}{*}{ Exporter $(\log )$ GDP per capita } & $-0.461 * * *$ & $-0.454 * * *$ & $-0.531 * * *$ & -0.096 & -0.072 & 0.045 & -0.219 \\
\hline & $(0.117)$ & $(0.077)$ & $(0.126)$ & $(0.190)$ & $(0.130)$ & $(0.214)$ & $(0.150)$ \\
\hline \multirow[t]{2}{*}{ Importer (log) GDP per capita } & $-0.223^{*}$ & $-0.113^{*}$ & $-0.303 * *$ & 0.114 & $0.246^{*}$ & 0.253 & \\
\hline & $(0.134)$ & $(0.068)$ & $(0.131)$ & $(0.187)$ & $(0.128)$ & $(0.190)$ & \\
\hline \multirow[t]{2}{*}{ Extensive margin of trade } & 0.430 & $0.510 *$ & $0.537 * *$ & 0.378 & 0.352 & 0.367 & -0.253 \\
\hline & $(0.268)$ & $(0.265)$ & $(0.268)$ & $(0.284)$ & $(0.271)$ & $(0.281)$ & $(0.344)$ \\
\hline \multirow[t]{2}{*}{ Exp. (log) Physical Capital / Labor ratio } & -0.067 & & -0.010 & -0.094 & & -0.165 & -0.033 \\
\hline & $(0.089)$ & & $(0.100)$ & $(0.104)$ & & $(0.134)$ & $(0.116)$ \\
\hline \multirow[t]{2}{*}{ Imp. (log) Physical Capital / Labor ratio } & 0.042 & & 0.125 & 0.038 & & -0.033 & \\
\hline & $(0.102)$ & & $(0.104)$ & $(0.120)$ & & $(0.123)$ & \\
\hline \multirow[t]{2}{*}{ Exp. (log) Human Capital / Labor ratio } & $0.799 * * *$ & & $0.942 * * *$ & $0.710 * *$ & & $0.651 *$ & 0.474 \\
\hline & $(0.256)$ & & $(0.290)$ & $(0.353)$ & & $(0.351)$ & $(0.299)$ \\
\hline \multirow[t]{2}{*}{ Imp. (log) Human Capital / Labor ratio } & 0.358 & & $0.473^{*}$ & 0.202 & & 0.138 & \\
\hline & $(0.241)$ & & $(0.283)$ & $(0.404)$ & & $(0.397)$ & \\
\hline \multirow[t]{2}{*}{$\mid \Delta(\log )$ Physical Capital / Labor ratio $\mid$} & & 0.013 & 0.059 & & 0.110 & 0.171 & \\
\hline & & $(0.095)$ & $(0.102)$ & & $(0.109)$ & $(0.130)$ & \\
\hline \multirow[t]{2}{*}{$\mid \Delta(\log )$ Human Capital / Labor ratio $\mid$} & & 0.146 & $0.607 * *$ & & 0.552 & 0.439 & \\
\hline & & $(0.247)$ & $(0.277)$ & & $(0.424)$ & $(0.424)$ & \\
\hline \multirow[t]{2}{*}{$\mid \Delta(\log )$ GDP per capita $\mid$} & & 0.174 & 0.109 & & -0.138 & -0.212 & \\
\hline & & $(0.113)$ & $(0.133)$ & & $(0.142)$ & $(0.169)$ & \\
\hline \multirow[t]{2}{*}{ Constant } & $0.453 * * *$ & $0.302 * * *$ & $0.299 * * *$ & & & & \\
\hline & $(0.039)$ & $(0.068)$ & $(0.066)$ & & & & \\
\hline Gravity variables & $\mathrm{x}$ & $\mathrm{x}$ & $\mathrm{x}$ & $\mathrm{x}$ & $\mathrm{x}$ & $\mathrm{x}$ & \\
\hline Agreement FEs & & & & $\mathrm{x}$ & $\mathrm{x}$ & $\mathrm{x}$ & \\
\hline Agr. $\times$ pair FEs & & & & & & & $\mathrm{x}$ \\
\hline Observations & 660 & 660 & 660 & 660 & 660 & 660 & 660 \\
\hline$R^{2}$ & 0.421 & 0.418 & 0.430 & 0.513 & 0.511 & 0.515 & 0.782 \\
\hline Within $R^{2}$ & & & & 0.176 & 0.173 & 0.180 & 0.124 \\
\hline $\ln \widehat{T o T}_{i}-\ln \widehat{T o T}_{j}$ & $13.895^{* *}$ & $14.007 * *$ & $13.782 * *$ & $13.854 * *$ & $14.105^{* *}$ & $13.856^{* *}$ & \\
\hline
\end{tabular}

Second-stage estimates are obtained using OLS with robust standard errors (reported in parentheses). "Gravity variables" (suppressed for brevity) include ln DIST, CONTIG, COLONY, LANG, LEGAL, and Prior Agreement. Full results available on request. $* p<0.10, * * p<.05, * * * p<.01$. $\dagger$ Also accounts for "globalization" effects.

in $(\log )$ per capita GDPs, in order to get at various potential dimensions of comparative advantage.

Data for each of these endowment measures is constructed using information from the Penn World

Table. The most notable finding here is that relative human capital endowments play a signifi- 
cant role in explaining heterogeneity across different agreements, as is picked up by columns 1 and 3. These results suggest that countries with strong respective comparative advantages in skillintensive versus non-skill-intensive industries tend to sign stronger FTAs with one another. The exporter human capital-to-labor ratio also appears to have some relevance for explaining heterogeneity within agreements as well (in columns 4 and 6). It does not appear to specifically induce asymmetries in FTA effects, however (in column 7).

\section{Out-of-sample Predictions \& Ex Ante Analysis}

This section performs two main exercises. We first develop and tune a simple, parsimonious prediction model for the effects of FTAs by dropping one agreement at a time and trying to predict its effects out-of-sample, using candidate predictors drawn from the main empirical results above. We then apply our model to the task of predicting the effects of TTIP on the trade volumes and welfare of each potential TTIP members and non-members in our sample. Notably, we find very large differences in predictions depending on whether we apply an average effect for TTIP versus specific predictions for TTIP's effects between members.

\subsection{Developing a Prediction Model}

Our out-of-sample analysis proceeds by dropping one agreement at a time and then trying to predict its effects based on a model fitted using the other agreements in the sample. For this exercise, we will draw on the various models used in our empirical second-stage analysis above. To keep the analysis compact, and to avoid concerns about overfitting, we strive to exploit only a few key regressors. We also try to use a balanced mix of both pair-specific as well as country-specific predictors, since our analysis have shown that both types of variables matter for explaining the effects of FTAs on trade. With these goals in mind, we examine a series of different models, each using a combination of (no more than) three bilateral variables, two exporter-specific predictors, and two importer-specific predictors. To validate the predictive power of each proposed model, we 
compute a simple linear fit from the following regression:

$$
\beta_{A: d}=\rho_{0}+\rho_{1} \cdot \widetilde{\beta}_{A: d}+e
$$

where $\beta_{A: d}$ is the first stage estimate for a directional pair $d$ within agreement $A$ and $\widetilde{\beta}_{A: d}$ is the corresponding out-of-sample prediction. We also focus only on the 5th through 95 th percentiles of our estimates, dropping the largest and smallest values. ${ }^{28}$

Table 9 shows the performance of various models we experimented with. For our criteria, we aimed for a set of predictors which: (i) performs well against other alternatives in terms of $R^{2}$; (ii) can be naturally motivated based on our empirical results from Section 5; (iii) contains at least some variables that were shown to be important for "within-agreement" heterogeneity (since a key part of our analysis will be to predict heterogeneity within TTIP). Our preferred model is "Model 3" from Table 6. This model specifically entails the following simple prediction specification:

$$
\begin{aligned}
\widetilde{\beta}_{A: d}= & \widetilde{\alpha}_{0}+\widetilde{\alpha}_{1} \ln \operatorname{DIST}_{i j}+\widetilde{\alpha}_{2} \text { First stage pair } \mathrm{FE}_{i j}+\widetilde{\alpha}_{3} \text { PriorFTA }_{i j}+\widetilde{\alpha}_{4} \mathrm{GDP}_{i} \\
& +\widetilde{\alpha}_{5} \mathrm{GDP} \text { per capita } \\
+ & \widetilde{\alpha}_{6} \mathrm{GDP}_{j}+\widetilde{\alpha}_{7} \ln \widehat{T o T}_{j}+v_{i j} .
\end{aligned}
$$

The model laid in (14) both synthesizes many of the key empirical insights we have accumulated thus far and performs reasonably well versus the other models examined in Table 9. All the predictors used in (14) were shown to be consistently significant throughout the preceding section, especially when we zeroed in on heterogeneity within agreements and within pairs in Tables 5 and 6. Partial effects should be smaller for countries that have a higher first stage pair fixed effect (indicating lower ex ante trade frictions), are further apart geographically, and/or if they already have an existing agreement in place. In addition, we also allow for asymmetries in FTA effects within pairs by including the GDPs of both partners, the GDP per capita of the exporter, and our (inverse) measure of the importing country's market power, $\ln \widehat{T o T}_{j}$. All else equal, trade agreements should

\footnotetext{
${ }^{28}$ Models perform similarly in terms of out-of-sample predictions regardless of whether we include outliers. What this buys us is, naturally, less likelihood of extreme values when we go to predict the effects of TTIP.
} 
Table 9: Out-of-sample Validation Results

\begin{tabular}{|c|c|c|c|c|c|}
\hline \multicolumn{6}{|c|}{ Selected Prediction Models and Model Fit Results } \\
\hline Model & Bilateral variables & Country-level variables & $\rho_{0}$ & $\rho_{1}$ & $R^{2}$ \\
\hline 1 & $\begin{array}{l}\text { lnDIST, Prior FTA, } \\
\text { First Stage Pair FEs }\end{array}$ & $\ln \widehat{T o T}_{i}, \ln \widehat{T o T}_{j}$ & $0.103 * * *$ & $0.662 * * *$ & 0.081 \\
\hline 2 & $\begin{array}{l}\text { lnDIST, Prior FTA, } \\
\text { First Stage Pair FEs }\end{array}$ & $\begin{array}{l}\log \mathrm{GDP}_{i}, \log \mathrm{GDP}_{j}, \\
\ln \widehat{T o T}_{i}, \ln \widehat{T o T}_{j}\end{array}$ & $0.050 *$ & $0.836 * * *$ & 0.194 \\
\hline $3 \dagger$ & $\begin{array}{l}\text { lnDIST, Prior FTA, } \\
\text { First Stage Pair FEs }\end{array}$ & $\begin{array}{l}\log \mathrm{GDP}_{i}, \log \mathrm{GDP}_{j}, \\
\log \text { p.c. } \mathrm{GDP}_{i}, \ln \widehat{T o T}_{j}\end{array}$ & $0.058 * *$ & $0.829 * * *$ & 0.222 \\
\hline 4 & $\begin{array}{l}\text { lnDIST, Ext. Margin, } \\
\text { First Stage Pair FEs }\end{array}$ & $\begin{array}{l}\log \mathrm{GDP}_{i}, \log \mathrm{GDP}_{j}, \\
\log \text { p.c. } \mathrm{GDP}_{i}, \ln \widehat{T o T}{ }_{j}\end{array}$ & $0.046^{* *}$ & $0.832 * * *$ & 0.213 \\
\hline 5 & $\begin{array}{l}\text { lnDIST, contig, } \\
\text { First Stage Pair FEs }\end{array}$ & $\begin{array}{l}\log \mathrm{GDP}_{i}, \log \mathrm{GDP}_{j}, \\
\log \text { p.c. } \mathrm{GDP}_{i}, \ln \widehat{T o T}{ }_{j}\end{array}$ & $0.052 * *$ & $0.827 * * *$ & 0.217 \\
\hline 6 & $\begin{array}{l}\text { InDIST, Prior FTA, } \\
\text { First Stage Pair FEs }\end{array}$ & $\begin{array}{l}\log \mathrm{GDP}_{i}, \log \mathrm{GDP}_{j}, \\
\mathrm{H} / \mathrm{L} \text { ratio }_{i}, \ln \widehat{T o T}_{j}\end{array}$ & $0.067 * *$ & $0.802 * * *$ & 0.209 \\
\hline
\end{tabular}

$\dagger$ Preferred prediction model.

$* p<0.10, * * p<.05, * * * p<.01$

have larger partial effects between larger countries and should be smaller when the exporter has a higher GDP per capita and/or when the importer's terms of trade are more sensitive to changes in trade policy.

Figure 2 then offers a visualization of the resulting predictive fit. Each data point in Fig. 2 represents a predicted FTA effect (indexed by the horizontal axis), which we compare with the actual estimate obtained from the first stage (indexed by the vertical axis). The coefficient on our predicted values, $\rho_{1}=0.829$, is positive and highly significant. The $R^{2}, 0.222$, also confirms we are able to predict a significant amount of variation in the effects of FTAs using our simple model; it compares favorably to the $R^{2}$ values we were able to obtain in Table 4 in our empirical analysis.

Before turning to TTIP, we acknowledge two important limitations of this approach. First, the predictive fit of our preferred model $\left(R^{2}=0.222\right)$ indicates we are only really able to predict a modest amount of the overall heterogeneity in the effects of free trade agreements. Obviously, if the $R^{2}$ of the predictive fit were our sole criterion, we could easily inflate the fit of our predictive model by adding many more variables on the righthand-side, including a rich set of fixed effects. ${ }^{29}$

\footnotetext{
${ }^{29}$ For example, an alternative approach would be to follow the second-stage analysis more closely by running separate out-of-sample predictions with agreement- and/or agreement-by-pair fixed effects to attempt to isolate each dimension of interest. In addition, we may also use directional country-specific fixed effects.
} 


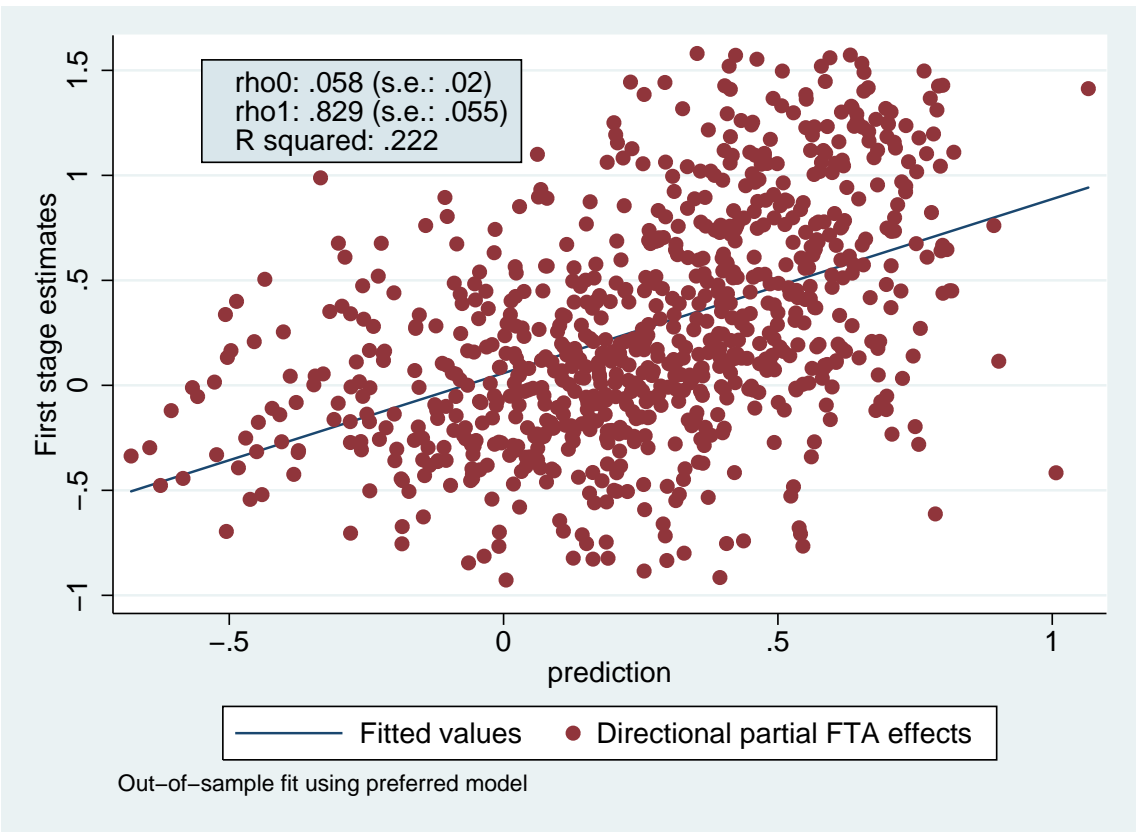

Figure 2: Out-of-sample Validation Results

However, this runs the risk of "overfitting" the model and, furthermore, leads us away from being able to provide an intuitive understanding of what factors are driving our predictions. A second caveat is that, because not all the individual directional FTA effects we computed in our first stage are positive, our methodology can and will predict negative partial effects for at least some TIIP pairs. We do not take a stand on why we observe negative FTA effects in our estimates. Our prior would ordinarily be that TTIP should generally lead to trade creation between all pairs. Where negative values are encountered, we take this to mean that trade creation is likely to be small. Overall, we are comfortable with each of these limitations and still feel like our approach is able to shed light on some novel and meaningful sources of predictive power.

\subsection{Predicting the Effects of TTIP}

Our task in this section is to predict the effects of TTIP, given different assumptions about how TTIP will affect trade barriers between the U.S. and its prospective TTIP partners in the E.U. In particular, we will explore two main scenarios. Under the "average" scenario, we base the change 
in trade barriers for all U.S./E.U. on our estimate of the overall average partial effect using (5). In other words, $\widehat{\tau}_{i j}^{-\theta}=e^{\beta_{\text {avg }}}=e^{0.188}$, for all U.S./E.U. pairs. Using an estimated average partial effect to predict partial effects of future agreements ex ante is an increasingly common practice, as noted in the Introduction. While it is widely understood that this approach is far from ideal, the current literature offers few alternatives for making more specific predictions about partial effects. ${ }^{30}$

Accordingly, under our second scenario, dubbed the "heterogeneous" scenario, we predict direction-pair-specific partial effects for TTIP using the insights from our prior analysis. In particular, we let $\widehat{\tau}_{i j}^{-\theta}=e^{\beta_{i j}}$, where $\beta_{i j}$ is computed using both the coefficients estimated from our preferred second-stage model as well as the $\rho$ 's associated with this model from our out-of-sample validation analysis. In other words,

$$
\beta_{i j}=0.058+0.829 \cdot \widetilde{\beta}_{T T I P: d}
$$

where $\widetilde{\beta}_{T T I P: d}$ is the fitted value for each directional pair $d$ within TTIP computed from our secondstage estimates. Essentially, we are using the linear regression results from (13) to determine how much weight we should place on our ability to predict heterogeneity in partial effects $\left(\rho_{1}=0.829\right)$, versus using a common average component $\left(\rho_{0}=0.058\right)$. We use the information on $\rho_{0}$ and $\rho_{1}$ in this way in the interest of providing additional conservatism.

The underlying regression coefficients used to compute $\widetilde{\beta}_{T T I P: d}$ are:

$$
\begin{gathered}
\widetilde{\beta}_{T T I P: d}=2.682-0.276 \cdot \ln \mathrm{DIST}_{i j}-0.191 \cdot \text { First stage pair } \mathrm{FE}_{i j}-0.127 \cdot \operatorname{PriorFTA}_{i j} \\
+0.125 \cdot \ln \mathrm{GDP}_{i}-0.156 \cdot \ln \mathrm{GDP} \text { p. } \mathrm{c}_{\cdot}+0.111 \cdot \ln \mathrm{GDP}_{j}-6.465 \cdot \ln \widehat{T o T}_{j}
\end{gathered}
$$

which are computed using the same specification and methodology as in (16), only now using all agreements in the sample, instead of excluding one at a time. All coefficient values shown in (16) are statistically different from zero at the $p<0.01$ significance level, except for $\ln \widehat{T o T}_{j}$, which has a $p$ value of 0.035 .

\footnotetext{
${ }^{30}$ Baier, Bergstrand and Clance (2015) is one exception, as we have discussed.
} 
The predicted partial effects for TTIP are then shown in Table 10. Notably, they are highly heterogeneous. The overall mean ( 0.153 if weighted by trade, 0.189 if not) is in the same ballpark as the overall average partial effect we estimated from the data (0.188). Consistent with what we saw previously with E.U. accession effects, the largest partial effects, in excess of 0.340, involve the Eastern European E.U. members Bulgaria, Romania, and Poland (with fellow Eastern European member Hungary not far behind). The smallest values, all negative, involve U.S. trade with both Ireland and Malta.

Table 10: Predicting the partial effects of TTIP

\begin{tabular}{|c|c|c|c|c|c|}
\hline Exporter & Importer & $\beta_{T T I P: d}$ & Exporter & Importer & $\beta_{T T I P: d}$ \\
\hline \multicolumn{6}{|c|}{ Predicted partial effects of TTIP (by TTIP pair) } \\
\hline United States & Austria & 0.157 & Austria & United States & 0.136 \\
\hline United States & Belgium-Luxembourg & 0.092 & Belgium-Luxembourg & United States & 0.084 \\
\hline United States & Bulgaria & 0.344 & Bulgaria & United States & 0.455 \\
\hline United States & Cyprus & 0.187 & Cyprus & United States & 0.191 \\
\hline United States & Denmark & 0.149 & Denmark & United States & 0.122 \\
\hline United States & Finland & 0.163 & Finland & United States & 0.142 \\
\hline United States & France & 0.200 & France & United States & 0.221 \\
\hline United States & Germany & 0.167 & Germany & United States & 0.183 \\
\hline United States & Greece & 0.289 & Greece & United States & 0.308 \\
\hline United States & Hungary & 0.222 & Hungary & United States & 0.288 \\
\hline United States & Ireland & -0.073 & Ireland & United States & -0.110 \\
\hline United States & Italy & 0.217 & Italy & United States & 0.235 \\
\hline United States & Malta & -0.084 & Malta & United States & -0.065 \\
\hline United States & Netherlands & 0.059 & Netherlands & United States & 0.046 \\
\hline United States & Poland & 0.414 & Poland & United States & 0.512 \\
\hline United States & Portugal & 0.282 & Portugal & United States & 0.319 \\
\hline United States & Romania & 0.360 & Romania & United States & 0.485 \\
\hline United States & Spain & 0.320 & Spain & United States & 0.339 \\
\hline United States & Sweden & 0.087 & Sweden & United States & 0.071 \\
\hline \multicolumn{6}{|c|}{ Summary statistics: } \\
\hline \multicolumn{3}{|c|}{ Simple } & \multicolumn{3}{|l|}{ Trade-weighted } \\
\hline \multicolumn{2}{|c|}{ Median $\beta_{T T I P: d}$ prediction: } & 0.189 & \multicolumn{2}{|c|}{ Median $\beta_{T T I P: d}$ prediction: } & 0.183 \\
\hline \multicolumn{2}{|c|}{ Mean $\beta_{T T I P: d}$ prediction: } & 0.198 & \multicolumn{2}{|c|}{ Mean $\beta_{T T I P: d}$ prediction: } & 0.153 \\
\hline \multicolumn{2}{|c|}{ Standard deviation: } & 0.152 & \multicolumn{2}{|l|}{ Standard deviation: } & 0.106 \\
\hline
\end{tabular}

$\beta_{T T I P: d}$ is a predicted partial effect of TTIP on all pairs of countries affected by TTIP. The United Kingdom is not included in TTIP. Trade frictions between EU countries are assumed to not be affected.

What explains the diversity in predictions across the various pairs? It cannot be variation in bilateral distance, since all European countries are collectively separated from the U.S. by the Atlantic. Nor is it due to the presence of an existing free trade agreement. Instead, these variables primarily pin down the overall level of TTIP's effects, across all pairs. The major source of 
heterogeneity across pairs is the first stage pair fixed effect, recovered from (9), representing $e x$ ante trade frictions between the different potential TTIP pairings. Ireland, for example, is already very tightly integrated with the U.S. in trade: for Ireland-U.S. trade, we obtain an ex ante level of trade integration (i.e., iceberg frictions raised to the minus $\theta$ ) between the U.S. and Ireland of $d_{\overline{U S, I R}}^{-\theta}=0.026$. While this may not, on the surface, seem like a large number, it is actually the largest of any U.S.-E.U. pair. ${ }^{31}$ The smallest index (0.001) is for the U.S.'s trade with Cyprus, along with, unsurprisingly, its trade with Bulgaria and Romania, followed closely by its trade with Poland (0.002). ${ }^{32}$ Looking at asymmetries within pairs, there does not appear to be a dominant pattern favoring either U.S. or E.U. exports. Instead, TTIP's partial effects will generally favor (on net) the U.S.'s exports to Northern European countries such as Austria, Finland, and the Netherlands, but will also favor imports from the Eastern European economies Bulgaria, Hungary, Poland, and Romania. Clearly, these asymmetry patterns directly reflect the broad differences in GDP per capita we observe across these different regions within Europe.

What about our control for the sensitivity of terms of trade? One might expect that, as the largest participant, the U.S. should have more "market power" ex ante with respect to its potential E.U. partners. Interestingly, our simulation approach shows this is not the case. A key aspect of TTIP's structure is that the U.S. gains every E.U. country as a new trade partners, whereas each individual E.U. member only gains 1. Therefore, all else equal, any U.S.-E.U. agreement would actually have a relatively balanced effect on terms of trade. Put another way, it is essentially the collective influence of the E.U. as a whole on U.S. terms of trade that matters here, more so than the influence of any one E.U. country. A novel aspect of our methodology is that we are able to capture this distinction.

For our general equilibrium prediction analysis, we will stick with the simple trade model implied by (1) and (2). In particular, we will maintain that labor is the only factor of production

\footnotetext{
${ }^{31}$ As has been observed by several authors-see, e.g., Anderson and van Wincoop (2004) and Head and Mayer (2013) — bilateral trade costs are still surprisingly large in the present day, even for nominally well-integrated countries.

${ }^{32}$ For a useful comparison using simple trade data: in 2006, trade with the U.S. made up only $3.9 \%$ of Bulgaria's manufacturing exports and $2.9 \%$ of its imports. For Ireland, meanwhile, the U.S. took in fully $19.7 \%$ of its exports and provided $11.6 \%$ of its imports.
} 
and that trade takes place in final goods only. As shown in Head and Mayer (2014), imposing market clearing on a model of this type then delivers a standard general equilibrium system that generalizes across a wide range of different models. While this simple framework omits several factors that have been shown to be important for gains from trade (e.g., multiple industries, trade in intermediates, etc.), it is widely accepted in the literature as a benchmark for computing the general equilibrium effects of trade policies. Furthermore, it will allow us to capture the basic point that, even when an agreement has the same partial effect on all trade flows, general equilibrium outcomes can still be quite heterogeneous.

As is now well-known, the competitive equilibrium in such a model can be described by the following system of equations,

$$
w_{i} L_{i}=\sum_{j} \pi_{i j} \cdot\left(w_{j} L_{j}+D_{j}\right) \quad \forall i
$$

where $\pi_{i j} \equiv A_{i} w_{i}^{-\theta} \tau_{i j}^{-\theta} / P_{j}^{-\theta}$ is the share of $j$ 's total expenditure on goods produced in origin country $i$. Note that we allow trade to be unbalanced. Total expenditure in $j$ is therefore comprised of an (endogenous) labor income term, $w_{j} L_{j}$, and an (exogenous) trade balance term $D_{j} .{ }^{33}$ What (17) says is that the total amount of output produced in origin $i, w_{i} L_{i}$, must be equal to the sum of expenditure on goods produced in $i$ across all destinations $j$.

The beauty of (17) is that it can solved (in changes) to predict general equilibrium effects of an FTA on both welfare and trade as a result of an FTA. To see this, first let $\widehat{x}=x^{\prime} / x$ denote the equilibrium change in a variable from an initial level $x$ to a new equilibrium level $x^{\prime}$ (i.e., the nowstandard "hat algebra" notation of Dekle, Eaton and Kortum, 2007). The equilibrium in changes version of (17) is therefore:

$$
Y_{i} \widehat{w}_{i}=\widehat{w}_{i}^{-\theta} \sum_{j} \frac{\pi_{i j} \cdot \widehat{\tau}_{i j}^{-\theta}}{\widehat{P}_{j}^{-\theta}} \cdot\left(Y_{j} \widehat{w}_{j}+D_{j}\right) \quad \forall i
$$

\footnotetext{
${ }^{33}$ An alternative method for modeling trade balances is to assume expenditure in $j$ is a constant share of $j$ 's output; that is, $E_{j}=d_{j} Y_{j}$, where $d_{j}$ in this case would be the (multiplicative) trade balance parameter.
} 
where $\widehat{P}_{j}^{-\theta}$ can be computed as:

$$
\widehat{P}_{j}^{-\theta}=\sum_{i} \pi_{i j} \widehat{w}_{i}^{-\theta} \widehat{\tau}_{i j}^{-\theta}
$$

Given initial trade shares $\left\{\pi_{i j}\right\}$, output levels $\left\{Y_{i}\right\}$, expenditure levels $\left\{E_{j}\right\}$, and a set of changes in trade barrier levels, $\left\{\widehat{\tau}_{i j}^{-\theta}\right\}$, one can solve the system defined by (18) and (19) for the resulting changes in wages $\left\{\widehat{w}_{i}\right\}$. With wages in hand, we then obtain the following expressions for the associated general equilibrium changes in both welfare levels and trade flows:

$$
\begin{aligned}
\text { GE Welfare Impact : } & \widehat{W}_{i}=\widehat{E}_{i} / \widehat{P}_{i} \\
\text { GE Trade Impact : } & \widehat{X}_{i j}=\frac{\widehat{w}_{i}^{-\theta} \widehat{\tau}_{i j}^{-\theta}}{\widehat{P}_{j}^{-\theta}} \cdot \widehat{E}_{j},
\end{aligned}
$$

where the change in national expenditure, $\widehat{E}_{i}$, is computed as $\left(Y_{i} \widehat{w}_{i}+D_{i}\right) / E_{i} \cdot{ }^{34}$ We will use the year 2006, the last year in our data, to compute the initial trade levels and trade balances. ${ }^{35}$ Finally, since (18) is non-linear in $\widehat{w}_{i}$, we require an assumption regarding the trade elasticity, $\theta$. Following the recommendations of Simonovska and Waugh (2014), we assume $\theta=4$.

Table 11 lists the predicted general equilibrium effects of TTIP, both for trade and for welfare, under the two noted scenarios. As is standard in this class of models, FTAs have a larger effect on trade flows than they do welfare, as the implied welfare cost of substituting to one's own suppliers is usually relatively small. ${ }^{36}$ The U.S., for example, experiences a large change in trade volumes including a $4.47 \%$ increase in the value of its exports - but only a $0.23 \%$ increase in its welfare, as buyer prices in the U.S. (i.e., $\left.P_{U S}\right)$ rise at more or less the same rate as U.S. wages.

\footnotetext{
${ }^{34}$ The downside of assuming linear trade balances in (17) is that computing changes in "welfare" requires an extra step. With balanced trade and/or multiplicative trade balances, welfare and real wages are one and the same: $\widehat{W}_{i}=$ $\widehat{w}_{i} / \widehat{P}_{i}$. Naturally, the computed changes in welfare and real wages are usually similar, although they may differ noticeably for countries with large trade imbalances.

${ }^{35}$ The limiting factor here is data on gross output for later years, especially for the U.S. Alternatively, we could use GDP to construct internal trade for a more recent year, as has been done in other studies. The theory calls for a measure of gross sales, however (i.e., gross output, since GDP measures value added).

${ }^{36}$ This result is an artifact of assuming a single differentiated good with a trade elasticity of 4 . If $\theta$ differs across industries, changes in trade for goods with lower values of $\theta$ can have very large welfare effects, as shown by Ossa (2015).
} 
Nonetheless, Table 11 reveals several key insights we wish to focus on. First, even in the "average" scenario, where all TTIP pairs enjoy a common partial effect, the general equilibrium implications of TTIP nonetheless introduce their own layer of heterogeneity. Usefully, this heterogeneity can largely be related back to a key aspect of our analysis, the level of ex ante trade frictions between countries. For example, the largest welfare effect is for Ireland, who enjoys a $0.83 \%$ increase in its welfare thanks to closer trade ties with the U.S. Intuitively, since Ireland already has the lowest ex ante trade barriers with the U.S., using a common partial effect for TTIP would eliminate a relatively larger portion of Ireland's remaining trade frictions with the U.S. than those of other E.U. members. ${ }^{37}$ Similarly, the lowest welfare gainers under the average scenario include Cyprus, Bulgaria, Greece, Poland, and Romania-countries with which the U.S.'s ex ante trade relations are not as strong.

Of course, these same close relations between the U.S. and Ireland also led us to predict a negative partial effect under the "heterogeneous" scenario. In turn, the subsequent welfare effect for Ireland is likewise predicted to be negative, completely flipping the prior result for Ireland under the "average" scenario. The case of Ireland thus illustrates the following conclusion: low ex ante trade frictions are associated with both small partial effects ex post as well as larger welfare effects ex post. Therefore, using a common average partial effect will tend to systematically overestimate welfare gains for country-pairs who are already well-integrated in trade. A similar principle also applies in reverse. The Eastern European E.U. members Bulgaria, Hungary, Poland, and Romania are among those that see the largest improvements in welfare from introducing heterogeneous partial effects, reflecting the large partial effects we predicted for these countries in Table 10. For non-TTIP countries, general equilibrium effects are relatively similar across scenarios. As one would expect, these countries all experience mild trade diversion and most experience small welfare losses. ${ }^{38}$ The largest losers notably major regional trade partners on either side of the Atlantic not included in the agreement, such as the EFTA countries Norway, Iceland, and Switzerland,

\footnotetext{
${ }^{37}$ This echoes an observation formalized by Baier, Bergstrand and Clance (2015): for the same (absolute) reduction in trade frictions, countries who start out with already-close trade relations gain more in terms of welfare.

${ }^{38}$ Bolivia, Colombia, and Ecuador actually see their welfare increase (despite having their real wages fall) as a result of TTIP. This phenomenon occurs because these countries have positive trade surpluses.
} 
the U.S.'s NAFTA partners Canada and Mexico, as as well as the United Kingdom (owing to its presumed "Brexit" from the E.U.)

\section{Conclusion}

How do free trade agreements actually affect trade between member countries? And can we convincingly predict the impact of major future agreements such as TPP and TTIP on member and non-member countries? This paper introduces a novel methodology intended to push forward our ability to answer each of these questions. Our two-stage approach not only allows us to shed light on several useful, intuitive determinants of the partial effects of FTAs, but also directly lends itself towards developing and validating an ex ante prediction model for predicting the effects of future agreements. Several notable aspects of the analysis include a novel set of theory-guided indices for predicting the magnitude of FTA partial effects, the ability to consider a wide variety of other possible sources of heterogeneity, and the opportunity to specifically examine determinants of heterogenous partial effects within the same agreement.

Still, many relevant questions remain seemingly just beyond our current reach. For example, there remains only so much we can say about which FTA provisions work in favor of creating trade versus inhibiting trade. It is also widely acknowledged that economic integration agreements have consequences for investment as well as trade. The consequences for investment, too, are likely very heterogeneous across agreements and may interact with the trade-creating effects of FTAs in ways we cannot capture in our current study. Furthermore, as shown in Anderson and Yotov (2016), FTAs can have very different effects across industries and these industry-level differences in turn have important consequences for quantifying the welfare impact of FTAs. Adapting our two-stage procedure to a similar industry-level perspective would be a natural extension of our methods. Including trade in agricultural products and services would make for similar improvements, especially trade in services, since services are an increasingly important component of both world trade and the objectives of new trade agreements. As new data on trade in services as well as FDI are becoming increasingly available, incorporating these various important elements will 
make for valuable new avenues for future research.

\section{References}

Aichele, Rahel, Gabriel J. Felbermayr, and Inga Heiland. 2014. "Going deep: The trade and welfare effects of TTIP."

Anderson, James E., and Douglas Marcouiller. 2002. "Insecurity and the Pattern of Trade: An Empirical Investigation." Review of Economics and Statistics, 84(2): 342-352.

Anderson, James E., and Eric van Wincoop. 2003. "Gravity with Gravitas: A Solution to the Border Puzzle." American Economic Review, 93(1): 170-192.

Anderson, James E., and Eric van Wincoop. 2004. "Trade Costs." Journal of Economic Literature, 42(3): 691-751.

Anderson, James E., and Yoto V. Yotov. 2010. "The Changing Incidence of Geography." American Economic Review, 100(5): 2157-86.

Anderson, James E., and Yoto V. Yotov. 2016. "Terms of Trade and Global Efficiency Effects of Free Trade Agreements, 1990-2002.” Journal of International Economics, (in press).

Anderson, James E., Mario Larch, and Yoto V. Yotov. 2015a. "On the Effects of the Transatlantic Trade and Investment Partnership on Trade and Growth." Unpublished Manuscript.

Anderson, James, Mario Larch, and Yoto V. Yotov. 2015b. "Estimating General Equilibrium Trade Policy Effects: GE PPML.” CESifo Working Paper No. 5592.

Arkolakis, Costas, Arnaud Costinot, and Andrés Rodríguez-Clare. 2012. "New Trade Models, Same Old Gains?" The American Economic Review, 102(1): 94-130.

Armington, Paul S. 1969. "A Theory of Demand for Products Distinguished by Place of Production.” Staff Papers (International Monetary Fund), 16(1): 159-178.

Arvis, Jean-François, and Ben Shepherd. 2013. "The Poisson quasi-maximum likelihood estimator: a solution to the 'adding up' problem in gravity models." Applied Economics Letters, 20(6): 515-519.

Bagwell, Kyle, and Robert W. Staiger. 1999. "An economic theory of GATT." The American Economic Review, 89(1): 215-248.

Bagwell, Kyle, and Robert W. Staiger. 2004. "Multilateral trade negotiations, bilateral opportunism and the rules of GATT/WTO." Journal of International Economics, 63(1): 1-29.

Bagwell, Kyle, and Robert W. Staiger. 2011. "What Do Trade Negotiators Negotiate About? Empirical Evidence from the World Trade Organization." The American Economic Review, 101(4): 1238-1273.

Baier, Scott L., and Jeffrey H. Bergstrand. 2007. "Do free trade agreements actually increase members' international trade?" Journal of International Economics, 71(1): 72-95.

Baier, Scott L., Jeffrey H. Bergstrand, and Matthew Clance. 2015. "Heterogeneous Economic Integration Agreements." mimeo.

Baier, Scott L., Jeffrey H. Bergstrand, and Michael Feng. 2014. "Economic integration agreements and the margins of international trade." Journal of International Economics, 93(2): 339-350.

Bergstrand, Jeffrey H., Mario Larch, and Yoto V. Yotov. 2015. "Economic Integration Agreements, Border Effects, and Distance Elasticities in the Gravity Equation." European Economic Review, 78.

Carrère, Cèline. 2006. "Revisiting the effects of regional trade agreements on trade flows with proper specification of the gravity model." European Economic Review, 50(2): 223-247. 
Carrère, Céline, Anja Grujovic, and Frédéric Robert-Nicoud. 2015. "Trade and frictional unemployment in the global economy."

Cheng, I. Hui, and Howard. J. Wall. 2005. "Controlling for Heterogeneity in gravity models of trade." Federal Reserve Bank of St. Louis Review, 87(1): 49-63.

Costinot, Arnaud, and Andrés Rodríguez-Clare. 2014. "Trade Theory with Numbers: Quantifying the Consequences of Globalization." Handbook of International Economics, 4: 197-261.

Dai, Mian, Yoto V. Yotov, and Thomas Zylkin. 2014. "On the trade-diversion effects of free trade agreements." Economics Letters, 122(2): 321-325.

Dekle, Robert, Jonathan Eaton, and Samuel Kortum. 2007. "Unbalanced Trade." American Economic Review, 97(2): 351-355.

Eaton, Jonathan, and Samuel Kortum. 2002. "Technology, Geography, and Trade." Econometrica, 70(5): 1741-1779.

Egger, Peter H., and Kevin E. Staub. 2014. "GLM estimation of trade gravity models with fixed effects." Mimeo, ETH Zurich.

Eicher, Theo S., and Christian Henn. 2011. "In search of WTO trade effects: Preferential trade agreements promote trade strongly, but unevenly." Journal of International Economics, 83(2): 137-153.

Fally, Thibault. 2015. "Structural gravity and fixed effects." Journal of International Economics, 97(1): 7685.

Felbermayr, Gabriel J., Benedikt Heid, Mario Larch, and Erdal Yalcin. 2014. "Macroeconomic Potentials of Transatlantic Free Trade: A High Resolution Perspective for Europe and the World." CESifo Working Paper 5019.

Frankel, Jeffrey A., and Shang-Jin Wei. 1997. "Regionalization of World Trade and Currencies: Economics and Politics." In The Regionalization of the World Economy. 189-226. University of Chicago Press.

Frankel, Jeffrey A., Ernesto Stein, and Shang-Jin Wei. 1997. Regional Trading Blocs in the World Economic System. Peterson Institute.

Fugazza, Marco, and Jean-Christophe Maur. 2008. "Non-tariff barriers in CGE models: How useful for policy?" Journal of Policy Modeling, 30(3): 475-490.

Ghosh, Sucharita, and Steven Yamarik. 2004. "Are regional trading arrangements trade creating?: An application of extreme bounds analysis." Journal of International Economics, 63(2): 369-395.

Hanushek, Eric A. 1974. "Efficient Estimators for Regressing Regression Coefficients." The American Statistician, 28(2): 66-67.

Head, Keith, and Thierry Mayer. 2013. "What separates us? Sources of resistance to globalization." Canadian Journal of Economics/Revue canadienne d'économique, 46(4): 1196-1231.

Head, Keith, and Thierry Mayer. 2014. "Gravity equations: Workhorse, toolkit, and cookbook." Handbook of International Economics, 4: 131-196.

Hummels, David, and Peter J. Klenow. 2005. “The Variety and Quality of a Nation's Exports.” The American Economic Review, 95(3): 704-723.

Kehoe, Timothy J., and Kim J. Ruhl. 2013. "How Important Is the New Goods Margin in International Trade?" Journal of Political Economy, 121(2): 358-392.

Kehoe, Timothy J., Jack Rossbach, and Kim J. Ruhl. 2015. "Using the new products margin to predict the industry-level impact of trade reform." Journal of International Economics, 96(2): 289-297.

Kohl, Tristan. 2014. "Do we really know that trade agreements increase trade?" Review of World Economics, 150(3): 443-469.

Kohl, Tristan, Steven Brakman, and Harry Garretsen. 2015. "Do Trade Agreements Stimulate Interna- 
tional Trade Differently? Evidence from 296 Trade Agreements." The World Economy.

Krugman, Paul. 1980. "Scale Economies, Product Differentiation, and the Pattern of Trade." The American Economic Review, 70(5): 950-959.

Larch, Mario, and Yoto Yotov. 2016. "General equilibrium trade policy analysis with structural gravity." WTO Working Paper ERSD-2016-08.

Lewis, Jeffrey B., and Drew A. Linzer. 2005. "Estimating regression models in which the dependent variable is based on estimates." Political Analysis, 13(4): 345-364.

Manova, Kalina. 2013. "Credit Constraints, Heterogeneous Firms, and International Trade." Review of Economic Studies, 80(2): 711-744.

Mansfield, Edward D., Helen V. Milner, and Jon C. Pevehouse. 2007. "Vetoing Co-operation: The Impact of Veto Players on Preferential Trading Arrangements." British Journal of Political Science, 37(03): 403432.

Melitz, Marc J., and Gianmarco I. P. Ottaviano. 2008. "Market Size, Trade, and Productivity.” Review of Economic Studies, 75(1): 295-316.

Melitz, Mark J. 2003. "The Impact of Trade on Intra-industry Reallocations and Aggregate Industry Productivity." Econometrica, 71: 1695-1725.

Nicita, Alessandro, and Marcelo Olarreaga. 2007. "Trade, Production, and Protection Database, 1976-2004." World Bank Econ Rev, 21(1): 165-171.

Piermartini, Roberta, and Yoto Yotov. 2016. "Estimating Trade Policy Effects with Structural Gravity." WTO Working Paper ERSD-2016-10.

Santos Silva, J. M. C., and Silvana Tenreyro. 2006. "The Log of Gravity." Review of Economics and Statistics, 88(4): 641-658.

Santos Silva, J. M. C., and Silvana Tenreyro. 2011. "Further simulation evidence on the performance of the Poisson pseudo-maximum likelihood estimator." Economics Letters, 112(2): 220-222.

Simonovska, Ina, and Michael E. Waugh. 2014. “The elasticity of trade: Estimates and evidence.” Journal of International Economics, 92(1): 34-50.

Soloaga, Isidro, and L. Alan Winters. 2001. "Regionalism in the nineties: What effect on trade?" The North American Journal of Economics and Finance, 12(1): 1-29.

Tinbergen, Jan. 1962. "An analysis of world trade flows." In Shaping the World Economy. 1-117. New York:Twentieth Century Fund.

Waugh, Michael. 2010. "International Trade and Income Differences." The American Economic Review, 100(5): 2093-2124.

White, Halbert. 1980. "A Heteroskedasticity-Consistent Covariance Matrix Estimator and a Direct Test for Heteroskedasticity." Econometrica, 48(4): 817-838.

Wooldridge, Jeffrey M. 2002. Econometric Analysis of Cross Section and Panel Data. Cambridge, MA:MIT Press.

Zylkin, Thomas. 2015. "Beyond Tariffs: Quantifying Heterogeneity in the Effects of Free Trade Agreements." mimeo. 
Table 11: General Equilibrium Predictions for the Effects of TTIP Percentage changes in trade and welfare, by country

"Average" Scenario "Heterogeneous" Scenario

$\Delta \%$ Exports $\Delta \%$ Imports $\Delta \%$ Welfare $\Delta \%$ Exports $\Delta \%$ Imports $\Delta \%$ Welfare

\begin{tabular}{|c|c|c|c|c|c|c|}
\hline & & & & & & \\
\hline Argentina & -0.10 & -0.10 & -0.01 & -0.08 & -0.08 & -0.01 \\
\hline Australia & -0.23 & -0.10 & 0.00 & -0.19 & -0.08 & 0.00 \\
\hline Austria & 0.73 & 0.70 & 0.15 & 0.54 & 0.51 & 0.10 \\
\hline Belgium-Luxembourg & 0.97 & 0.98 & 0.12 & 0.48 & 0.48 & 0.06 \\
\hline Bolivia & -0.35 & -0.11 & 0.01 & -0.30 & -0.09 & 0.01 \\
\hline Brazil & -0.20 & -0.26 & -0.01 & -0.17 & -0.22 & -0.01 \\
\hline Bulgaria & 0.50 & 0.37 & 0.04 & 1.36 & 0.99 & 0.14 \\
\hline Canada & -0.43 & -0.42 & -0.06 & -0.39 & -0.37 & -0.05 \\
\hline Chile & -0.13 & -0.17 & -0.01 & -0.09 & -0.11 & -0.01 \\
\hline China & -0.13 & -0.29 & -0.02 & -0.11 & -0.25 & -0.02 \\
\hline Colombia & -0.30 & -0.13 & 0.01 & -0.26 & -0.11 & 0.01 \\
\hline Costa Rica & -0.27 & -0.24 & -0.02 & -0.15 & -0.13 & 0.00 \\
\hline Cyprus & 0.46 & 0.13 & 0.01 & 0.42 & 0.12 & 0.01 \\
\hline Denmark & 0.83 & 0.74 & 0.14 & 0.54 & 0.49 & 0.09 \\
\hline Ecuador & -0.19 & -0.05 & 0.02 & -0.14 & -0.04 & 0.02 \\
\hline Egypt & -0.08 & -0.04 & -0.01 & -0.03 & -0.01 & -0.01 \\
\hline Finland & 0.82 & 0.98 & 0.12 & 0.66 & 0.79 & 0.10 \\
\hline France & 1.14 & 1.08 & 0.14 & 1.37 & 1.29 & 0.16 \\
\hline Germany & 1.16 & 1.59 & 0.22 & 1.13 & 1.55 & 0.22 \\
\hline Greece & 1.12 & 0.34 & 0.01 & 2.05 & 0.61 & 0.04 \\
\hline Hungary & 0.45 & 0.44 & 0.07 & 0.71 & 0.70 & 0.11 \\
\hline Iceland & -0.27 & -0.10 & -0.04 & -0.09 & -0.03 & -0.02 \\
\hline Indonesia & -0.12 & -0.14 & -0.01 & -0.10 & -0.11 & -0.01 \\
\hline Ireland & 1.62 & 2.80 & 0.83 & -0.85 & -1.46 & -0.43 \\
\hline Israel & -0.36 & -0.40 & -0.04 & -0.31 & -0.34 & -0.03 \\
\hline Italy & 1.04 & 1.15 & 0.09 & 1.37 & 1.52 & 0.12 \\
\hline Japan & -0.16 & -0.29 & -0.02 & -0.13 & -0.24 & -0.01 \\
\hline Jordan & -0.77 & -0.24 & -0.01 & -0.72 & -0.22 & -0.01 \\
\hline Kuwait & -0.15 & -0.08 & -0.01 & -0.13 & -0.07 & -0.01 \\
\hline Malaysia & -0.16 & -0.22 & -0.03 & -0.13 & -0.18 & -0.03 \\
\hline Malta & 1.27 & 0.76 & 0.18 & -0.62 & -0.37 & -0.14 \\
\hline Mexico & -0.47 & -0.47 & -0.07 & -0.43 & -0.42 & -0.06 \\
\hline Morocco & -0.08 & -0.05 & -0.03 & -0.07 & -0.04 & -0.03 \\
\hline Myanmar & 0.12 & 0.03 & 0.01 & 0.14 & 0.03 & 0.00 \\
\hline Netherlands & 0.98 & 0.99 & 0.33 & 0.29 & 0.29 & 0.09 \\
\hline Norway & -0.18 & -0.11 & -0.05 & -0.12 & -0.08 & -0.03 \\
\hline Philippines & -0.14 & -0.18 & -0.03 & -0.10 & -0.12 & -0.02 \\
\hline Poland & 0.44 & 0.36 & 0.03 & 1.42 & 1.15 & 0.12 \\
\hline Portugal & 0.83 & 0.58 & 0.05 & 1.57 & 1.10 & 0.12 \\
\hline Qatar & -0.28 & -0.08 & -0.02 & -0.26 & -0.07 & -0.03 \\
\hline Romania & 0.56 & 0.35 & 0.02 & 1.62 & 1.01 & 0.12 \\
\hline Singapore & -0.10 & -0.11 & -0.02 & -0.08 & -0.10 & -0.01 \\
\hline South Korea & -0.10 & -0.17 & -0.01 & -0.09 & -0.13 & -0.01 \\
\hline Spain & 0.78 & 0.54 & 0.04 & 1.63 & 1.12 & 0.11 \\
\hline Sweden & 0.97 & 1.23 & 0.20 & 0.32 & 0.40 & 0.06 \\
\hline Switzerland & -0.19 & -0.20 & -0.03 & -0.14 & -0.15 & -0.02 \\
\hline Thailand & -0.12 & -0.16 & -0.02 & -0.11 & -0.14 & -0.02 \\
\hline Tunisia & -0.04 & -0.03 & -0.04 & -0.02 & -0.02 & -0.04 \\
\hline Turkey & -0.06 & -0.04 & -0.02 & -0.05 & -0.03 & -0.02 \\
\hline United Kingdom & -0.17 & -0.13 & -0.03 & -0.12 & -0.09 & -0.02 \\
\hline United States & 4.47 & 2.64 & 0.23 & 3.68 & 2.18 & 0.19 \\
\hline Uruguay & -0.17 & -0.13 & -0.01 & -0.14 & -0.11 & -0.01 \\
\hline Rest of the World & -0.19 & -0.06 & 0.00 & -0.15 & -0.05 & 0.00 \\
\hline $\mathrm{EU}$ & 0.91 & 0.93 & 0.13 & 0.84 & 0.85 & 0.11 \\
\hline TTIP & 1.59 & 1.42 & 0.17 & 1.38 & 1.23 & 0.14 \\
\hline Non-TTIP & -0.18 & -0.22 & -0.02 & -0.16 & -0.18 & -0.02 \\
\hline World & 0.78 & 0.78 & 0.08 & 0.68 & 0.68 & 0.07 \\
\hline
\end{tabular}




\section{Appendix A: Data}

\section{Table 12: Included Countries}

Main sample (52 countries/regions): Argentina, Australia, Austria, Bulgaria, Belgium-Luxembourg, Bolivia, Brazil, Canada, Switzerland, Chile, China, Colombia, Costa Rica, Cyprus, Germany, Denmark, Ecuador, Egypt, Spain, Finland, France, United Kingdom, Greece, Hungary, Indonesia, Ireland, Iceland, Israel, Italy, Jordan, Japan, South Korea, Kuwait, Morocco, Mexico, Malta, Myanmar, Malaysia, Netherlands, Norway, Philippines, Poland, Portugal, Qatar, Romania, Singapore, Sweden, Thailand, Tunisia, Turkey, Uruguay, United States

"Rest of World” (17 countries/regions): Cameroon, Hong Kong, India, Iran, Kenya, Sri Lanka, Macau, Mauritius, Malawi, Niger, Nigeria, Nepal, Panama, Senegal, Trinidad \& Tobago, Tanzania, South Africa

\section{Table 13: Included Agreements}

\begin{tabular}{lcl}
\hline $\begin{array}{l}\text { Multilateral Trade Blocs } \\
\text { Agreement }\end{array}$ & Year & Member Countries \\
\hline ASEAN $^{*}$ & 2000 & Indonesia, Malaysia, Myanmar, Philippines, Singapore, Thailand \\
Agadir & 2006 & Egypt, Jordan, Morocco, Tunisia \\
Andean Community ${ }^{\dagger}$ & 1993 & Bolivia, Colombia, Ecuador \\
CEFTA & 1993 & Poland (1993-2004), Hungary (1993-2004), Romania (1997-2004), \\
& & Bulgaria (1998-2004) \\
EFTA & 1960 & Norway, Switzerland, Iceland (1970), Portugal (1960-1986), \\
& & Austria (1960-1995), Sweden (1960-1995) Finland (1986-1995). \\
EU ${ }^{\dagger}$ & 1958 & Belgium-Luxembourg, France, Italy, Germany, Netherlands, Denmark (1973), \\
& & Ireland (1973), United Kingdom (1973), Greece (1981), Portugal (1986), \\
& Spain (1986), Austria (1995), Finland (1995), Sweden (1995), \\
& Cyprus (2004), Malta (2004), Hungary (2004), Poland (2004) \\
& 1995 & Argentina, Brazil, Uruguay \\
Mercosur ${ }^{* \dagger}$ & 1994 & Canada, Mexico, U.S. \\
NAFTA & 1998 & Egypt, Kuwait, Jordan, Morocco, Qatar, Tunisia \\
\hline Pan Arab Free Trade Area
\end{tabular}

EFTA's outside agreements: Turkey (1992), Bulgaria (1993), Hungary (1993), Israel (1993), Poland (1993), Romania (1993), Mexico (2000), Morocco (2000), Singapore (2003)

EU's outside agreements: EFTA (1973), Cyprus (1988), Hungary (1994), Poland (1994), Bulgaria (1995), Romania (1995), Turkey (1996) ${ }^{\dagger}$, Tunisia (1998), Israel (2000), Mexico (2000), Morocco (2000), Chile (2003), Egypt (2004)

Other agreements: Australia-Singapore (2003), Australia-Thailand (2005), Australia-U.S. (2005), Bulgaria-Israel (2002), Bulgaria-Turkey (1998), Canada-Chile (1997), , Canada-Costa Rica (2003), Canada-Israel (1997), Canada-U.S. (1989), Chile-China (2006), Chile-Costa Rica (2002), Chile-Mexico (1999), Chile-Singapore (2006), Chile-South Korea (2004), Chile-U.S. (2004), Colombia-Mexico (1995), Costa Rica-Mexico (1995), Egypt-Turkey (2006), Hungary-Israel (1998), Hungary-Turkey (1998), Israel-Mexico (2000), Israel-Poland (1998), Israel-Romania (2001), Israel-Turkey (2001), Japan-Mexico (2005), Jordan-U.S. (2002), Mercosur-Andean (2005), Mercosur-Bolivia (1996), Mercosur-Chile (1996), Mexico-Uruguay (2005), Morocco-U.S. (2006), Poland-Turkey (2000), Romania-Turkey (1998), Singapore-U.S. (2004), Tunisia-Turkey (2006)

*For these two blocs, we follow the NSF-Kellogg Database in using, respectively, the date at which ASEAN "moved toward" becoming a free trade area and the date at which Mercosur became a customs union.

${ }^{\dagger}$ Denotes a deeper level of agreement (e.g., a customs union). 


\section{Appendix B: Auxiliary Results}

In this Appendix, we detail some additional experiments that involve varying the method used to compute our second-stage estimates. In the main text, we considered only (unweighted) estimates using OLS and heteroskedasticity-robust standard errors (using the standard error correction of White, 1980). Here, for completeness, we consider the two other alternatives for weighting the first stage examined in Lewis and Linzer (2005): a standard WLS ("Weighted Least Squares") estimator - which weights each observation by the inverse of the first stage standard error - and a special FGLS ("Feasible Generalized Least Squares") estimator proposed by Hanushek (1974) for problems of this type.

For concreteness, we will refer to the (lack of) weighting method associated with OLS as "W1". A second, widely used weighting method for two-stage estimation is the standard WLS estimator, or "W2":

$$
\mathbf{W 2}: \text { weight }_{A: d}=\frac{1}{\sqrt{\sigma_{I, A: d}^{2}}},
$$

where $\sigma_{I, A: d}$ is the standard error associated with each $\beta_{A: d}$ estimated in the first stage. W2 has the desirable property that more precisely estimated $\beta_{A: d}$ 's from the first stage are given more weight in determining second-stage estimates. Unfortunately, this weighting method has the drawback of assuming all model uncertainty in the second stage is due to the error associated with $\beta_{A: d}$. Accordingly, a third alternative, first suggested by Hanushek (1974), is

$$
\mathbf{W 3}: \text { weight }_{A: d}=\frac{1}{\sqrt{\sigma_{I, A: d}^{2}+\hat{\sigma}_{I I}^{2}}},
$$

where $\hat{\sigma}_{I I}^{2}$ is an unbiased estimate of the the second-stage error variance, assuming homoskedastic errors. Weighting using W3 is an example of a "Feasible Generalized Least Squares" estimator, which we will abbreviate as "FGLS". Intuitively, FGLS varies the degree of weighting depending on the relative magnitudes of the (individual) first stage error variances vs. the (total) second stage error variance; it therefore nests both WLS and OLS as extreme cases.

As we see from Tables 14 and 15, our FGLS estimates are a closer match for our original OLS estimates than the additional WLS estimates computed using W2, reinforcing our initial motivation

for using OLS as our baseline. Nonetheless, all three weighting methods generally produce very similar results. 
Table 14: Second-stage Estimates: Alternate Weighting - WLS

\begin{tabular}{|c|c|c|c|c|c|c|c|}
\hline & Dependent & ariable: Fir & t stage direc & ional FTA e & timates & & \\
\hline & (1) & (2) & (3) & (4) & $(5)$ & (6) & (7) \\
\hline First stage pair $\mathrm{FE} \dagger$ & $\begin{array}{l}-0.078 * * * \\
(0.019)\end{array}$ & $\begin{array}{l}-0.264 * * * \\
(0.028)\end{array}$ & $\begin{array}{l}-0.230 * * * \\
(0.039)\end{array}$ & & $\begin{array}{l}-0.297 * * * \\
(0.031)\end{array}$ & $\begin{array}{l}-0.237 * * * \\
(0.040)\end{array}$ & \\
\hline $\ln \widehat{T o T}_{i}$ & $\begin{array}{l}2.234 \\
(4.198)\end{array}$ & $\begin{array}{l}4.538 \\
(3.993)\end{array}$ & $\begin{array}{l}9.075 * * \\
(4.524)\end{array}$ & $\begin{array}{l}11.801 * * \\
(4.724)\end{array}$ & $\begin{array}{l}2.687 \\
(4.137)\end{array}$ & $\begin{array}{l}8.640 * \\
(4.632)\end{array}$ & $\begin{array}{l}11.681 \text { ** } \\
(4.727)\end{array}$ \\
\hline $\ln \widehat{T O T}_{j}$ & $\begin{array}{l}-11.919 * * * \\
(3.268)\end{array}$ & $\begin{array}{l}-7.217 * * \\
(3.541)\end{array}$ & $\begin{array}{l}-2.454 \\
(4.232)\end{array}$ & & $\begin{array}{l}-9.385^{* * *} \\
(3.558)\end{array}$ & $\begin{array}{l}-2.994 \\
(4.303)\end{array}$ & \\
\hline $\ln$ DIST & & $\begin{array}{l}-0.339 * * * \\
(0.031)\end{array}$ & $\begin{array}{l}-0.199 * * * * \\
(0.057)\end{array}$ & & $\begin{array}{l}-0.316^{* * * *} \\
(0.032)\end{array}$ & $\begin{array}{l}-0.185^{* * * *} \\
(0.060)\end{array}$ & \\
\hline CONTIG & & $\begin{array}{l}0.177^{* *} \\
(0.076)\end{array}$ & $\begin{array}{l}-0.039 \\
(0.083)\end{array}$ & & $\begin{array}{l}0.142^{*} \\
(0.073)\end{array}$ & $\begin{array}{l}-0.046 \\
(0.081)\end{array}$ & \\
\hline COLONY & & $\begin{array}{l}-0.021 \\
(0.065)\end{array}$ & $\begin{array}{l}0.056 \\
(0.079)\end{array}$ & & $\begin{array}{l}-0.033 \\
(0.065)\end{array}$ & $\begin{array}{l}0.046 \\
(0.079)\end{array}$ & \\
\hline LANG & & $\begin{array}{l}0.109 * \\
(0.066)\end{array}$ & $\begin{array}{l}0.091 \\
(0.072)\end{array}$ & & $\begin{array}{l}0.102 \\
(0.064)\end{array}$ & $\begin{array}{l}0.091 \\
(0.072)\end{array}$ & \\
\hline LEGAL & & $\begin{array}{l}-0.010 \\
(0.056)\end{array}$ & $\begin{array}{l}0.121 * * \\
(0.061)\end{array}$ & & $\begin{array}{l}-0.009 \\
(0.055)\end{array}$ & $\begin{array}{l}0.119^{*} \\
(0.061)\end{array}$ & \\
\hline Prior Agreement & & $\begin{array}{l}-0.167 * * * \\
(0.044)\end{array}$ & $\begin{array}{l}0.012 \\
(0.062)\end{array}$ & & $\begin{array}{l}-0.202 * * * \\
(0.045)\end{array}$ & $\begin{array}{l}0.004 \\
(0.063)\end{array}$ & \\
\hline Exporter (log) Real GDP & & $\begin{array}{l}0.176 * * * \\
(0.020)\end{array}$ & $\begin{array}{l}0.160 * * * \\
(0.023)\end{array}$ & $\begin{array}{l}0.038^{*} \\
(0.023)\end{array}$ & $\begin{array}{l}0.128 * * * \\
(0.028)\end{array}$ & $\begin{array}{l}0.144 * * * \\
(0.031)\end{array}$ & $\begin{array}{l}0.058^{*} \\
(0.035)\end{array}$ \\
\hline Importer (log) Real GDP & & $\begin{array}{l}0.138^{* * * *} \\
(0.019)\end{array}$ & $\begin{array}{l}0.123 * * * \\
(0.022)\end{array}$ & & $\begin{array}{l}0.137 * * * \\
(0.018)\end{array}$ & $\begin{array}{l}0.122 * * * \\
(0.022)\end{array}$ & \\
\hline Exporter (log) GDP per capita & & $\begin{array}{l}-0.140 * * * \\
(0.042)\end{array}$ & $\begin{array}{l}-0.060 \\
(0.078)\end{array}$ & $\begin{array}{l}-0.172 * * * \\
(0.043)\end{array}$ & $\begin{array}{l}-0.195 * * * \\
(0.045)\end{array}$ & $\begin{array}{l}-0.079 \\
(0.080)\end{array}$ & $\begin{array}{l}-0.142 * * \\
(0.059)\end{array}$ \\
\hline Importer (log) GDP per capita & & $\begin{array}{l}0.029 \\
(0.033)\end{array}$ & $\begin{array}{l}0.108 \\
(0.067)\end{array}$ & & $\begin{array}{l}0.045 \\
(0.033)\end{array}$ & $\begin{array}{l}0.112^{*} \\
(0.068)\end{array}$ & \\
\hline Extensive margin of trade & & & & & $\begin{array}{l}0.608 * * * \\
(0.191)\end{array}$ & $\begin{array}{l}0.193 \\
(0.192)\end{array}$ & $\begin{array}{l}-0.256 \\
(0.243)\end{array}$ \\
\hline Constant & $\begin{array}{l}0.220 * * * \\
(0.023)\end{array}$ & $\begin{array}{l}0.251 * * * \\
(0.022)\end{array}$ & & & $\begin{array}{l}0.252 * * * \\
(0.022)\end{array}$ & & \\
\hline Agreement FEs & & & $\mathrm{x}$ & & & $\mathrm{x}$ & \\
\hline Agr. $\times$ pair FEs & & & & $\mathrm{x}$ & & & $\mathrm{x}$ \\
\hline Observations & 908 & 898 & 898 & 898 & 898 & 898 & 898 \\
\hline$R^{2}$ & 0.034 & 0.252 & 0.439 & 0.727 & 0.261 & 0.440 & 0.728 \\
\hline Within $R^{2}$ & & & 0.140 & 0.067 & & 0.141 & 0.069 \\
\hline $\ln \widehat{T o T}_{i}-\ln \widehat{T o T}_{j}$ & $14.153 * *$ & $11.755^{* *}$ & $11.529 * *$ & & $12.072 * *$ & $11.634 * *$ & \\
\hline
\end{tabular}

Second-stage estimates are obtained using Weighted Least Squares (WLS), weighted by inverse first stage standard error. Robust standard errors reported in parentheses. * $p<0.10$, ** $p<.05, * * * p<.01$

$\dagger$ Also accounts for "globalization" effects. 
Table 15: Second-stage Estimates: Alternate Weighting - FGLS

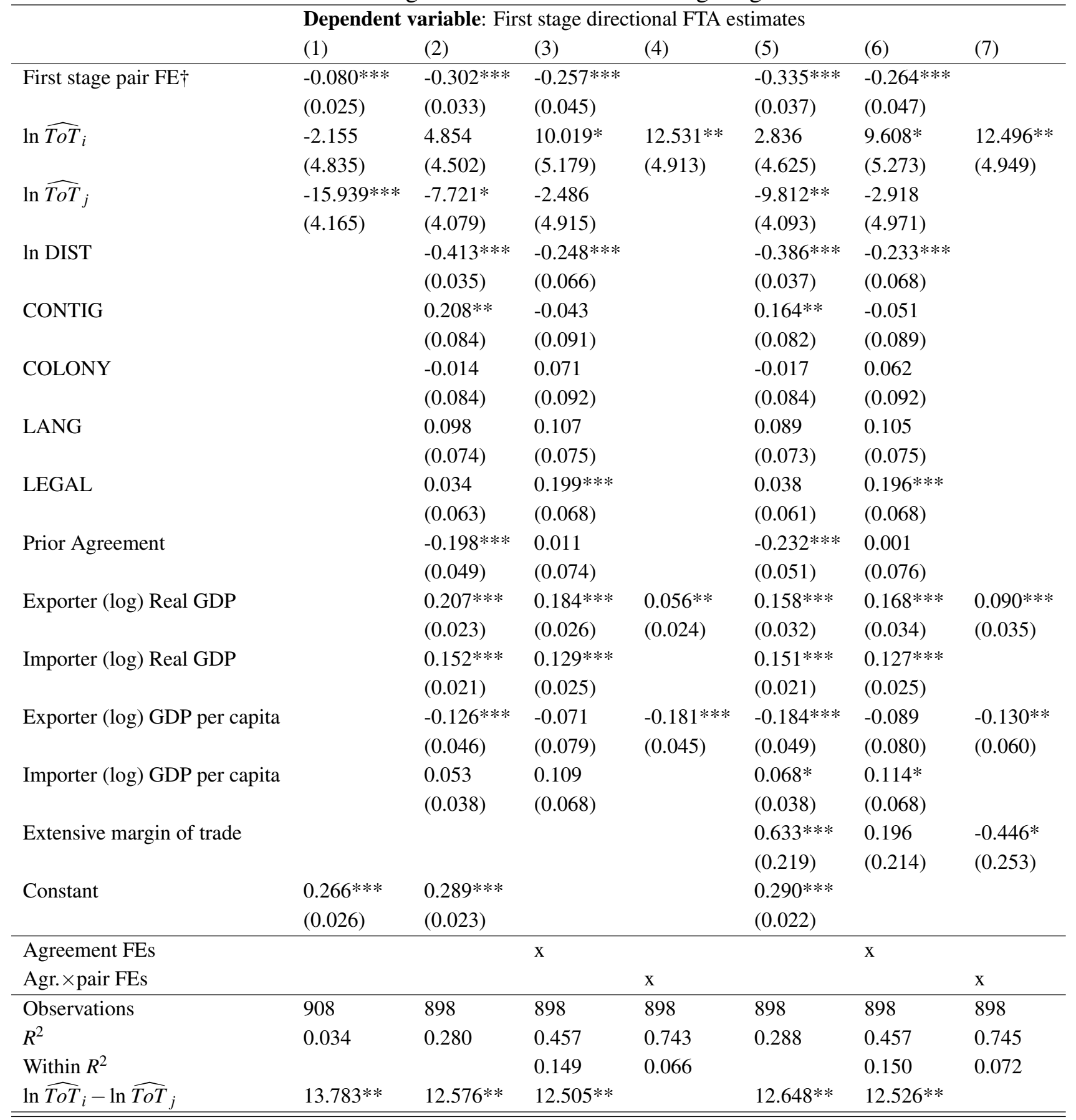

Second-stage estimates are obtained using a Feasible Generalized Least Squares (FGLS) method proposed by Hanushek (1974) for cases in which the dependent variable has been estimated with error in a prior stage. Robust standard errors reported in parentheses. * $p<0.10, * * p<.05, * * * p<.01$

$\dagger$ Also accounts for "globalization" effects. 